\title{
The Role of Monetary Aggregates in the Policy Analysis of the Swiss National Bank
}

\author{
Gebhard Kirchgässner $^{a}$ and Jürgen Wolters ${ }^{b}$
}

JEL-Classification: E41, E52

Keywords: Stability of Money Demand, Monetary Aggregates and Inflation

\section{Introduction}

From 1975 until 1999 the Swiss National Bank (SNB) performed monetary targeting for different monetary aggregates. The SNB aimed to control M1 growth from 1975 to 1978, base money growth from 1980 to 1999 and additionally M3 growth from 1997 to 1999 . Since 2000 a new monetary policy strategy has been implemented with price stability as highest priority. ${ }^{1}$ Price stability is defined as follows: Headline consumer price index grows less than two percent per year. Inflation forecasts for three years ahead are published twice a year. These forecasts are compared with the definition of price stability. If it is expected that the inflation rate will deviate for a longer time from the goal of price stability monetary policy is adjusted. Various indicators and models are used to forecast inflation. Among these indicators monetary aggregates play a prominent role since it is argued that they provide useful leading information on long-term inflation trends. This is quite in line with Friedman's (1963, p. 17) famous statement that "inflation is always and everywhere a monetary phenomenon".

University of St. Gallen, Swiss Institute for International Economics and Applied Economic Research (SIAW-HSG), Leopoldina and CESifo. Mailing Address: Prof. Dr. Gebhard Kirchgässner, University of St. Gallen, SIAW-HSG, Bodanstrasse 8, CH-9000 St. Gallen, Switzerland, Gebhard.Kirchgaessner@unisg.ch.

b Freie Universität Berlin and SIAW-HSG, respectively. Mailing Address: Prof. Dr. Jürgen Wolters, Freie Universität Berlin, Institute of Statistics and Econometrics, Boltzmannstrasse 20, D-14195 Berlin, Germany, Juergen.Wolters@fu-berlin.de. - We thank the Swiss National Bank for providing the data, and Sylvia Kaufmann (Austrian National Bank) as well as Samuel Reynard (Swiss National Bank) for helpful comments and suggestions.

1 See, for example, Jordan et al. (2009). 
The importance of money growth and/or excess money measures has been discussed in various papers: see, for example, BALTENSPERGER et al. (2001), JordAN et al. (2001), Reynard (2007) ${ }^{2}$ for Switzerland, Trecroci and Vega (2002), Gerlach and Svensson (2003), Hofmann (2006), Kaufmann and Kugler (2008), as well as Carstensen et al. (2009) for the euro area, and Nelson (2003) as well as Estrella and Mishrin (1997) for the US.

REYNARD (2007) showed that M2 excess liquidity is able to assess policy stance as well as potential inflation and output developments in Switzerland. A systematic analysis of the indicator properties of money growth and excess money for Switzerland has been given by Baltensperger et al. (2001) and Jordan et al. (2001) for M3 for the periods 1978 (1) to 1999 (2) and 1975 (1) to 2000 (2) respectively using seasonally adjusted data. Both papers came to the conclusion that for monetary policy decisions it is important to take money growth and excess money into account. This result is based on data coming from the monetary targeting regime of the SNB. Now we have data available from the new policy regime of the SNB and it might be interesting to analyse whether these earlier findings survive. Moreover, we are going to investigate not only M3 but also M1 and M2. We will use seasonally unadjusted data for the period from the first quarter of 1983 to the third quarter of 2008. With such data, updates are straightforward since no further data transformations and changes in earlier observations are needed. ${ }^{3}$

In a first step we investigate whether stable (long-run) money demand relations for M1, M2 and M3 exist and whether these are controllable by instruments of the SNB. ${ }^{4}$ These preconditions are necessary to derive meaningful measures of excess money. Since we find such stable relations, in a second step, we analyse the information content of money growth and excess money for future inflation. Due to the financial crisis, nominal monetary aggregates M1 and M2 increased dramatically since the end of 2008. Therefore, we also present ex ante inflation forecasts employing the most actual data available.

2 In this paper, results for the European area as well as the United States are also given.

3 At the actual end of the sample period seasonally adjusted data are generated with asymmetric filters having the drawback that artificial leads or lags may be produced, in particular, if they are combined with seasonally unadjusted data like interest rates.

4 Money demand functions for Switzerland are estimated, for example, by Peytrignet and Stahel (1998) with seasonally unadjusted data from 1977 (1) to 1997 (4) for M2 and M3, Baltensperger et al. (2001) for M3 with seasonally adjusted data from 1978 (1) to 1999 (2), as well as Assenmacher-Wesche (2008) for M2 using also seasonally adjusted data from 1976 (1) to 2006 (2). For an overview of earlier work on Swiss money demand functions see Gerlach-Kristen (2001), who also presents estimates for M3 with annual data ranging from 1936 to 1995. 
The paper is organized as follows. The data and its properties are described in the next section (Section 2). In Section 3, the money demand relations are specified, estimated and tested. In Section 4, the empirical importance of the three monetary aggregates as information variables for future inflation is investigated for our sample period. Additionally, ex ante forecasts are given. The last section summarises and concludes (Section 5).

\section{Data and Preliminary Analysis}

All data comes from the data base of the SNB. All monetary aggregates exclude Liechtenstein. M1 includes currency, demand deposits and transaction accounts, M2 is M1 plus savings deposits without pension funds accounts and M3 is M2 plus time deposits. The short term interest rate is the end-of-month 3-month London Interbank Offered Rate (LIBOR) for Swiss francs. This is the operating target rate of the SNB. The long-term interest rate is the yield on 10-year federal government bonds.

All these time series are given in monthly frequency. For temporal aggregation from monthly to quarterly data we apply systematic sampling, meaning that we use the value of the respective last month as the quarterly value. In contrast to averaging over the quarter this method does not create distortions with respect to lead-lag relations, as has been shown by KirChGässner and Wolters (1992) as well as RAJAGURU and AbEYSINGHe (2008). To construct real monetary aggregates we apply the implicit deflator of gross domestic product (GDP) which is the ratio of nominal and real gross domestic product multiplied by 100 with the base year 2000. As usual we take logarithms of monetary aggregates, output and the price level. These variables are denoted as $m i, i=1,2,3, y$, and $p$ respectively.

A visual impression of the data is given in Figures 1 and 2 presenting the levels and the first differences. Output $(y)$ and real money aggregates $(m i-p, i=1,2,3)$ show the typical trending behaviour but with a strong decline for real M1 and M2 since 2005 accommodated by an increase in the short ( $r s)$ and long-term interest rate $(r l)$. Moreover, output exhibits strong seasonality.

The results of formal unit root testing with an Augmented Dickey-Fuller test $^{5}$ are given in Table 1 . The lags are chosen in such a way that the residuals of the test equations are empirically white noise. The critical values for the models including seasonal dummies come from Hylleberg et al. (1990, Table 1a). For

5 For performing unit root tests see, for example, KirchGässner and Wolters (2007, chapter 5). All calculations are done with EViews Version 6. 
Figure 1: Levels of Variables

Log of real M1

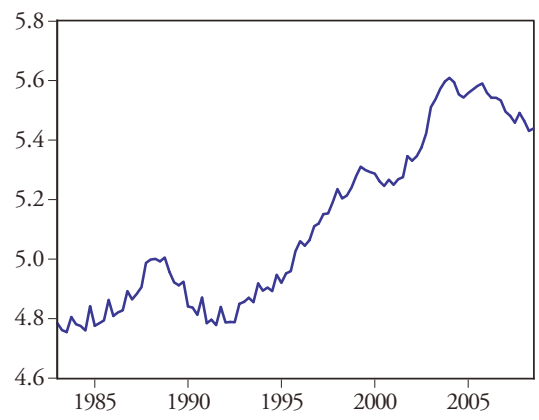

Log of real M3

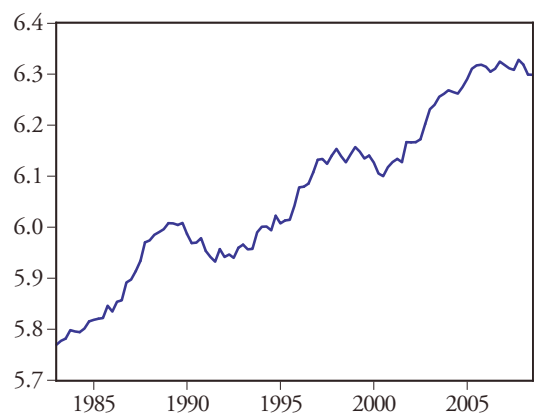

3-month interest rate

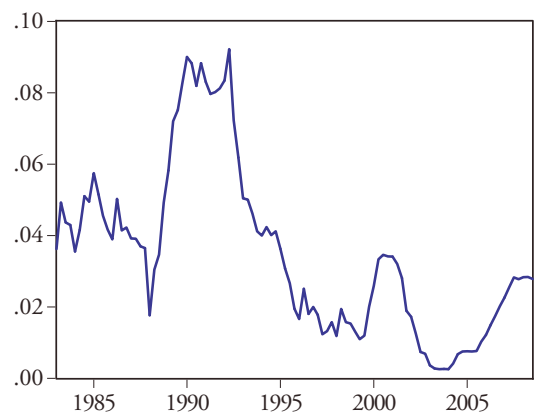

Log of real M2

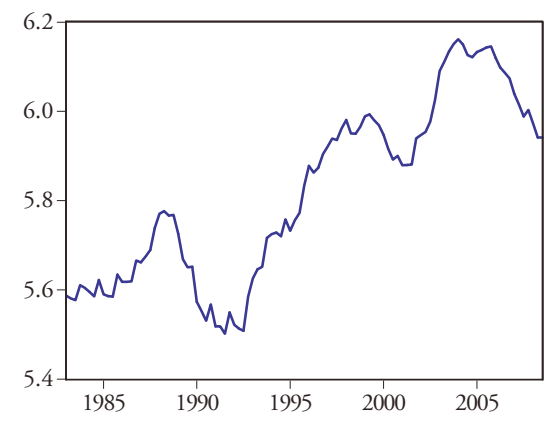

Log of real GDP

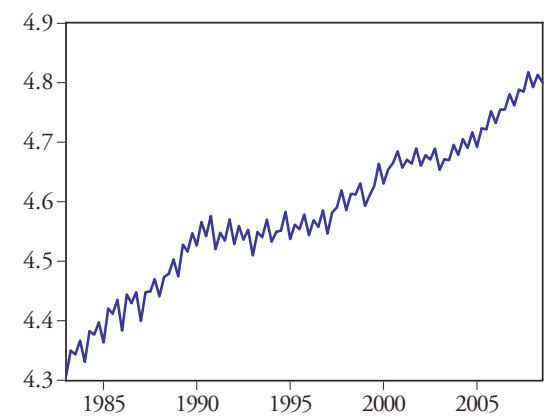

10 -year government bond rate

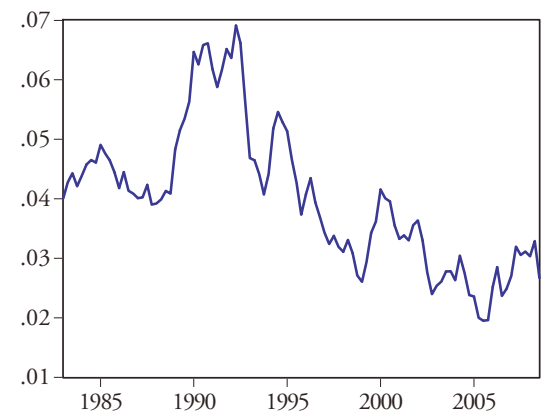


Figure 2: First Differences of Variables
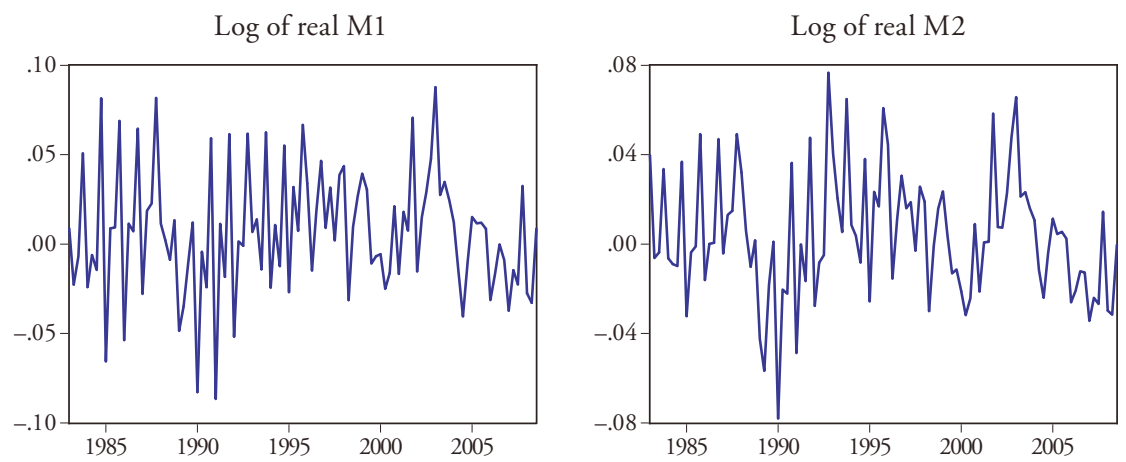

Log of real M3

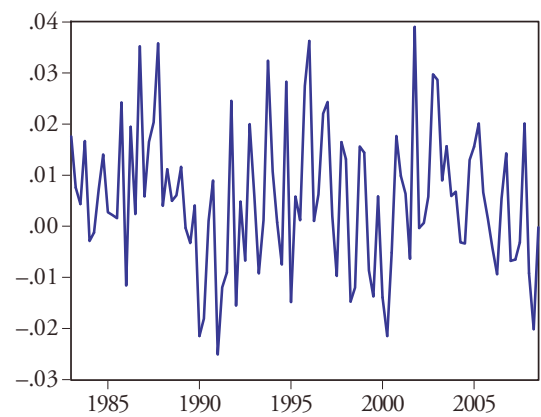

Log of real GDP

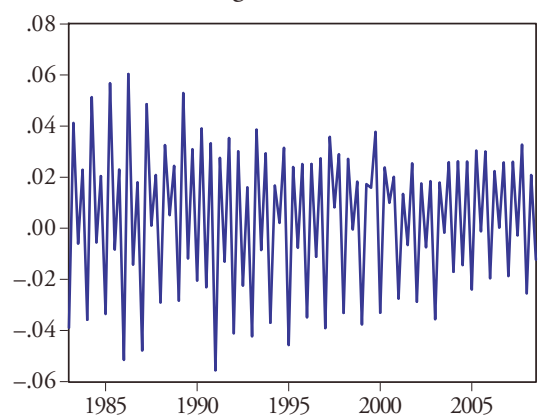

3-month interest rate

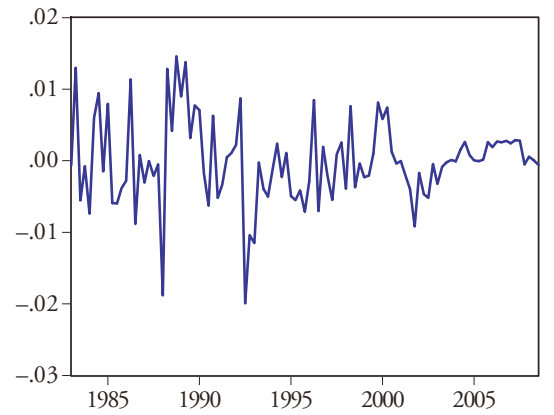

10-year government bond rate

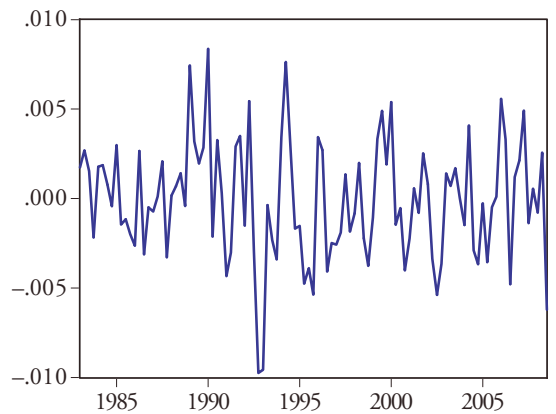


the models without seasonal dummies the critical values from MacKinnon (1996) are used. The results show clear evidence that for the levels the unit root hypothesis cannot be rejected whereas for the first differences this hypothesis is strongly rejected. Therefore, we conclude that all variables are non-stationary but their first differences are stationary, and this means that they behave as variables integrated of order one (I(1)). ${ }^{6}$ The only exception is the spread which is stationary.

Table 1: Augmented Dickey Fuller Tests 1983(1)-2008(3)

\begin{tabular}{llll}
\hline & Deterministic & Lags & t-statistic \\
\hline$m 1-p$ & constant, trend, seasonal dummies & $1,2,4$ & -2.71 \\
$\Delta(m 1-p)$ & constant, seasonal dummies & $1-3$ & $-3.16^{*}$ \\
$m 2-p$ & constant, trend, seasonal dummies & $1-4$ & -3.10 \\
$\Delta(m 2-p)$ & constant, seasonal dummies & 1,3 & $-3.58^{* *}$ \\
$m 3-p$ & constant, trend, seasonal dummies & $1,2,4,6$ & -2.76 \\
$\Delta(m 3-p)$ & constant, seasonal dummies & $1-3,6$ & $-3.13^{*}$ \\
$y$ & constant, trend, seasonal dummies & 3,4 & -2.91 \\
$\Delta y$ & constant, seasonal dummies & $1-3$ & $-3.81^{* *}$ \\
$r s$ & constant & $1-2$ & -1.79 \\
$\Delta r s$ & none & 1 & $-5.40^{* *}$ \\
$r 1$ & constant & 1,5 & -1.19 \\
$\Delta r 1$ & none & 4 & $-7.85^{* *}$ \\
$r s-r 1$ & none & 2 & $-2.27^{*}$ \\
\hline
\end{tabular}

Notes: ${ }^{*},{ }^{* *}$ denotes rejection of the null hypothesis of a unit root at the 5 or 1 percent level, respectively. Critical values are given in Hylleberg et al. (1990) and MacKinnon (1996).

6 Note that the outcomes of unit root tests and cointegration analyses are not an invariant property of the underlying variables but are strongly depending on the sample period and the frequency of the observations. See, for example, Juselius (1999). 


\section{Money Demand}

\subsection{Theoretical Considerations}

We apply a widely used specification of money demand as our starting point. According to Ericsson (1998) the specification of the demand for monetary aggregates leads to a long-run relation of the following form

$$
m i_{t}-p_{t}=a_{0}+a_{1} y_{t}+a_{2} r s_{t}+a_{3} r l_{t}
$$

where $m i, i=1,2,3$ are nominal money balances taken in logarithms, $p$ is the logarithm of the price level, and $y$ the logarithm of an income measure in real terms, representing the transaction volume in the economy. Opportunity costs of holding money are approximated by long $(r l)$ and short $(r s)$ term interest rates. The index $t$ denotes time.

Price homogeneity is imposed as a long-run condition. It is expected that the scale variable $y$ has a positive effect on nominal and real money balances $\left(\alpha_{1}>0\right)$. Very often a unit income elasticity is supposed theoretically, meaning that $\alpha_{1}=1$. The parameters $\alpha_{2}$ and $\alpha_{3}$ denote the semi-elasticities with respect to the opportunity costs of holding short and long-term financial assets which are expected to be negative. If, however, the short-term interest rate is a proxy for the own rate of interest of holding money, $\alpha_{2}$ should be positive.

\subsection{Cointegration Analysis}

According to the unit root tests in Table 1, all relevant variables behave as I(1) time series. Therefore, we first apply the JoHANSEN (1995) trace test to investigate whether long-run relations according to (1) exist. ${ }^{7}$ In systems including only $(m i-p), i=1,2,3$, and $y$, we do not find significant and economically meaningful cointegration relations. Thus, we need at least one further I(1) variable to find a cointegration relation that is a stationary linear combination of these variables. Since the spread between the long and short-term interest rate is stationary (compare Table 1) both interest rates are driven by the same stochastic trend. To get a minimal representation, in the next step, we investigate systems including $\left\{m i-p, y, r s_{t}\right\}$ as well as $\left\{m i-p, y, r l_{t}\right\}, i=1,2,3$. All models with the short-term rate outperform those with the long-term rate with respect

7 For performing cointegration tests and estimating the long-run parameters see, for example, KirChgäsSNER and Wolters (2007, chapter 6). 
to statistical significance and economic interpretation. All systems include an unrestricted constant and centred seasonal dummies, S1, S2, S3, which have the advantage that the estimated constant is free from seasonal effects. For M1 and M2 an impulse dummy D031 is also included. It takes the value one for the first quarter of 2003 and zero elsewhere. The reason for including this variable is that the SNB reduced the short-term interest rate dramatically in 2003 which introduced a more than expected increase in $\mathrm{M} 1$ and $\mathrm{M} 2{ }^{8}$ The lag order for all vector autoregressive models (VAR) in levels is one according to the ScHWARZ (1978) criterion (SC).

In Table 2, the results of the trace tests are presented together with likelihood ratio tests (LR) on unit income elasticity and weak exogeneity of income and interest rate. There is clear evidence of one cointegration relation between $m i-p, y$, and $r s$ for $i=1,2,3$. Moreover, for all three monetary aggregates the hypothesis of weak exogeneity of $y$ and $r s$ cannot be rejected. This means that only money adjusts to the long-run relation, i.e., the estimated equation can be interpreted as a money demand relation. For M1 a unit income elasticity cannot be rejected ( $p$-value 0.88 ) whereas for M2 this hypothesis is strongly rejected. For M3 the unit income elasticity can be rejected at the 5 percent level, but the joint hypothesis (unit elasticity and weak exogeneity) is not rejected; its $p$-value is 0.13 .

JoHANSEN's (1995) reduced rank maximum likelihood (ML) estimator is the standard approach to estimate the long-run parameters. However, the ML estimator should be applied with caution because it can produce extremely distorted and unreliable estimates in small samples, as BRÜGgEMANN and LÜTKEPOHL (2005) have shown. To overcome this problem, these authors recommend a two step generalized least squares estimator which is more robust in this regard. We use this so-called S2S estimator as a cross-check to the ML results as well as the single equation approach by Sтоск (1987). Single equation error-correction models are admissible since real money is the only endogenous variable in our systems.

The results are presented in Table 3 . The influence of the short-term interest rate is significantly negative in all cases. Thus, the short-term interest rate is no proxy for the own rate of holding money but a measure of opportunity costs. Moreover, since we used the LIBOR as short-term interest rate which is the operational target of the $\mathrm{SNB}$, the precondition of controllability of money demand by the SNB is fulfilled. For M1, the estimates of the different approaches lead to very similar results with income elasticities near one if they are estimated 
Table 2: Cointegration Tests for $\{m i-p, y, r s\}$ Unrestricted Constant and Centred Seasonal Dummies, 1983(1)-2008(3)

\begin{tabular}{lccc}
\hline & M1* & M2* & M3 \\
VAR lag order (SC) & 1 & 1 & 1 \\
\hline & \multicolumn{3}{c}{ Trace statistics } \\
Rank $\leq 0$ & 38.53 & 76.60 & 41.89 \\
& {$[0.00]$} & {$[0.00]$} & {$[0.00]$} \\
Rank $\leq 1$ & 11.92 & 13.56 & 16.70 \\
& {$[0.16]$} & {$[0.10]$} & {$[0.03]$} \\
\hline \multirow{3}{*}{ LR Statistic } & & Tests of unit income elasticity & \\
& 0.023 & 37.996 & 3.689 \\
& {$[0.88]$} & {$[0.00]$} & {$[0.05]$} \\
\hline \multirow{3}{*}{ LR Statistic } & Tests of weak exogeneity of income and interest rate \\
& 0.563 & 1.915 & 0.328 \\
& {$[0.75]$} & {$[0.38]$} & {$[0.85]$} \\
\hline \multirow{2}{*}{ LR Statistic } & & Combined tests & \\
& 0.576 & 45.954 & 5.712 \\
& {$[0.90]$} & {$[0.00]$} & {$[0.13]$} \\
\hline
\end{tabular}

Note: The numbers in brackets are the p-values.

* Including D031

unrestrictedly. Interest rate elasticities range from -0.20 to -0.27 percent using the mean for $r s$ which is about 3 percent in the sample period. For M2, the estimates of the income elasticity are in the range from 0.51 to 0.64 . These values are in line with the corresponding parameter in the inventory model for money holding of BAUMOL (1952) and ToBIN (1956). The interest rate elasticities amount to about -0.2 percent. For M3, we find a large difference between the unrestricted ML and S2S estimates for income parameters ( 0.4 versus 1.1$)$ and interest rate parameters $(-5.7$ versus -1.8$)$. All the other approaches show results similar to S2S. 
Table 3: Estimation Results: Long-Run Relations (1983(1)-2008(3))

\begin{tabular}{|c|c|c|c|c|c|}
\hline & $\begin{array}{c}\mathrm{ML} \\
\text { (unrestricted) }\end{array}$ & $\begin{array}{c}\text { S2S } \\
\text { (unrestricted) }\end{array}$ & $\begin{array}{c}\text { ML } \\
\text { (restricted) }\end{array}$ & $\begin{array}{c}\text { Stock } \\
\text { (unrestricted) }\end{array}$ & $\begin{array}{c}\text { Stock } \\
\text { (restricted) }\end{array}$ \\
\hline & \multicolumn{5}{|c|}{ M1 } \\
\hline$m 1-p$ & 1.000 & 1.000 & 1.000 & 1.000 & 1.000 \\
\hline$y$ & $\begin{array}{l}-1.043 \\
(0.18)\end{array}$ & $\begin{array}{c}-1.317 \\
(0.15)\end{array}$ & -1.000 & -1.257 & -1.000 \\
\hline \multirow[t]{2}{*}{$r s$} & $\begin{array}{l}8.596 \\
(0.95)\end{array}$ & $\begin{array}{l}6.756 \\
(0.79)\end{array}$ & $\begin{array}{l}9.029 \\
(0.89)\end{array}$ & 6.885 & 7.761 \\
\hline & \multicolumn{5}{|c|}{ M2 } \\
\hline$m 2-p$ & 1.000 & 1.000 & 1.000 & 1.000 & \\
\hline$y$ & $\begin{array}{r}-0.540 \\
(0.06)\end{array}$ & $\begin{array}{r}-0.605 \\
(0.06)\end{array}$ & $\begin{array}{r}-0.505 \\
(0.06)\end{array}$ & -0.640 & \\
\hline \multirow[t]{2}{*}{$r s$} & $\begin{array}{l}6.740 \\
(0.31)\end{array}$ & $\begin{array}{l}6.375 \\
(0.29)\end{array}$ & $\begin{array}{l}6.951 \\
(0.339)\end{array}$ & 5.897 & \\
\hline & \multicolumn{5}{|c|}{ M3 } \\
\hline$m 3-p$ & 1.000 & 1.000 & 1.000 & 1.000 & 1.000 \\
\hline$y$ & $\begin{array}{c}-0.427 \\
(0.18)\end{array}$ & $\begin{array}{l}-1.091 \\
(0.07)\end{array}$ & -1.000 & -0.814 & -1.000 \\
\hline$r s$ & $\begin{array}{l}5.699 \\
(0.92)\end{array}$ & $\begin{array}{l}1.759 \\
(0.34)\end{array}$ & $\begin{array}{l}2.913 \\
(0.39)\end{array}$ & 3.261 & 2.362 \\
\hline
\end{tabular}

Note: The numbers in parentheses are the standard errors of the estimated parameters.

\subsection{Error Correction Models}

Since income and the short-term interest rate are weakly exogenous (see Table 2), we can estimate single equation money demand relations without loss of efficiency. This approach has also the advantage to investigate easily the stability of these relations. According to the Sтоск (1987) procedure, we estimate single equation error correction models by ordinary least squares. We regress the changes of real money on the one period lagged levels of real money, real income, and the short-term interest rate as well as on lagged changes of these variables and additionally lagged changes of the long-term interest rate. Naturally, a constant, centred seasonal dummies, and for M1 and M2 also D031 are included. The lag structure is chosen such that the residuals are empirically white noise. For M3 it 
turned out that $\Delta r l_{t-1}$ is only significant since the first quarter of 2000. This is modelled by introducing a shift dummy S001 having the value of one since this quarter and zero before.

The estimates and specification tests are presented in Table 4. For M1 and M3 we impose a unit income elasticity after testing for this property with a Wald test. The null hypothesis cannot be rejected with $p$-values of 0.32 for M1 and 0.42 for M3, whereas for M2 it is clearly rejected with a $p$-value of 0.0001 . The error correction coefficients for M1 and M3 are significant at the 5 percent level and the one for M2 at the 1 percent level. ${ }^{9}$ According to these negative values real money adjusts to the long-run equilibrium for all three monetary aggregates. The long-run money demand equations (with standard errors in parentheses) are derived as (compare also Table 3):

$$
\begin{aligned}
& m 1_{t}-p_{t}=\underset{(0.06)}{0.881+}+y_{t}-\underset{(1.15)}{7.761 r s_{t}}+e c 1_{t}, \\
& m 2_{t}-p_{t}=\underset{(0.42)}{3.104}+\underset{(0.09)}{0.640 y_{t}}-\underset{(0.45)}{5.897 r s_{t}}+e c 2, \\
& m 3_{t}-p_{t}=\underset{(0.02)}{1.596+}+y_{t}-\underset{(0.43)}{2.362} r s_{t}+e c 3_{t},
\end{aligned}
$$

with eci, $i=1,2,3$, being the corresponding equilibrium errors as measures of real excess money. As theoretically expected the interest rate elasticities are decreasing with broader monetary aggregates. Standard specification tests are largely supportive for these error correction equations which are presented in Table 4. For the Lagrange Multiplier (LM) test for no autocorrelation in the residuals up to order 1,4 , and 8 the $p$-values in brackets show that no problems with autocorrelated residuals occur. Also, the null hypothesis of the ARCH-test of no conditional heteroscedasticity in the residuals can never be rejected at the 5 percent level, and the Jarque-Bera (J.-B.) test indicates that the estimated residuals are normally distributed. The Ramsey RESET test does not point to a misspecification of the equations.

We also tested whether there exists a break in the parameters in 2000(1), when the SNB introduced its new monetary policy framework. For all monetary aggregates the Chow Forecast test is not able to reject the null hypothesis of no break in the parameters. The same result holds for the Chow Breakpoint test with the

9 The critical values for these tests are given in BANARJEE et al. (1998). 
Table 4: Money Demand Equations (1983(1)-2008(3))

$$
\begin{aligned}
& \Delta(m 1-p)_{t}=\underset{(-3.72)}{0.088(m 1-p-y)_{t-1}-0.685 r s_{t-1}-\underset{(-3.50)}{0} 0.561 \Delta y_{t-1}} \\
& +0.225 \Delta(m 1-p)_{t-4}+0.078+0.100 D 031_{t} \\
& \text { (2.56) (4.06) (4.31) } \\
& -0.028 S 1_{t}-0.054 S 2_{t}-0.011 S 3_{t}+\hat{u}_{t} \text {, } \\
& R^{2}=0.578, \text { J.-B. }=1.699 \text { [0.45], } \operatorname{RESET}(1)=0.315 \text { [0.58], } \\
& \mathrm{LM}(1)=0.114[0.74], \operatorname{LM}(4)=0.208 \text { [0.93], } \operatorname{LM}(8)=0.721 \text { [0.67], } \\
& \operatorname{ARCH}(1)=3.29 \text { [0.07], } \operatorname{ARCH}(4)=1.522[0.20] \text {, } \\
& \text { Chow Forecast Test 2000(1) : } 0.815 \text { [0.74], } \\
& \text { Chow Breakpoint Test 2000(1) : } 0.934 \text { [0.50]. }
\end{aligned}
$$

$$
\begin{aligned}
& \Delta(m 2-p)_{t}=-0.213(m 2-p)_{t-1}+0.136 y_{t-1}-1.256 r s_{t-1} \\
& -\underset{(-3.48)}{2.006} \Delta r l_{t-1}+\underset{(2.27)}{0.188} \Delta(m 2-p)_{t-4}+\underset{(5.46)}{0.661}+\underset{(3.32)}{0.058 D 031_{t}} \\
& -0.028 S 1_{t}-0.022 S 2_{t}-0.021 S 3_{t}+\hat{u}_{t} \text {, } \\
& \begin{array}{lll}
(-5.07) & (-3.77) \quad(-3.85)
\end{array} \\
& R^{2}=0.626 \text {, J.-B. }=2.909 \text { [0.23], } \operatorname{RESET}(1)=0.456[0.50] \text {, } \\
& \mathrm{LM}(1)=0.328 \text { [0.57], } \operatorname{LM}(4)=0.882[0.48], \operatorname{LM}(8)=0.426[0.90] \text {, } \\
& \operatorname{ARCH}(1)=0.102[0.75], \operatorname{ARCH}(4)=1.944[0.11] \text {, } \\
& \text { Chow Forecast Test 2000(1): } 1.045 \text { [0.43], } \\
& \text { Chow Breakpoint Test 2000(1): } 2.110 \text { [0.03]. }
\end{aligned}
$$

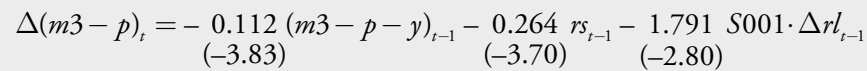

$$
\begin{aligned}
& +\underset{(2.04)}{0.184 \Delta(m 3-p)_{t-1}}+\underset{(2.63)}{0.242 \Delta(m 3-p)_{t-4}}+\underset{(3.93)}{0.178}
\end{aligned}
$$

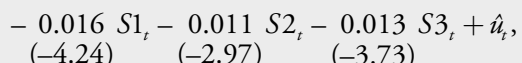

$$
\begin{aligned}
& R^{2}=0.488, \text { J.-B. }=1.227 \text { [0.54], } \operatorname{RESET}(1)=0.054 \text { [0.82], } \\
& \mathrm{LM}(1)=3.387(0.07), \operatorname{LM}(4)=1.120[0.35], \operatorname{LM}(8)=0.843 \text { [0.57], } \\
& \operatorname{ARCH}(1)=0.496[0.48], \operatorname{ARCH}(4)=2.115[0.09] \text {, } \\
& \text { Chow Forecast Test 2000(1) : } 0.950 \text { [0.56], } \\
& \text { Chow Breakpoint Test 2000(1) : } 0.744 \text { [0.67]. }
\end{aligned}
$$

Notes: The numbers in parentheses are the $t$-statistics of the estimated parameters, the numbers in brackets the $p$-values of the corresponding test statistics. 
exception of M2 where the null hypothesis can be rejected with a $p$-value of 0.03 . However, the CUSUM of squares test in Figure 3 does not indicate any structural break in the regression coefficients. Moreover, Figures $4 \mathrm{a}$ to $4 \mathrm{c}$, where the recursive estimates of the long-run coefficients in the error correction equations are plotted, show no signs of instability. Overall, the empirical evidence in favour of stable money demand equations for M1, M2, and M3 are strongly supported by the error correction approach. Thus, the second precondition to get useful excess money measures is also fulfilled.

\section{Monetary Measures as Information Variables}

In the following we will investigate whether monetary indicators can be used as information variables to provide a guide for the conduct of monetary policy, i.e., whether they help to explain future inflation.

\subsection{Descriptive Analysis}

Figures $5 \mathrm{a}$ to $5 \mathrm{c}$ show the objective variable, the annual consumer price inflation,

$$
\pi_{t}=100\left(p c_{t}-p c_{t-4}\right)
$$

with pc being the logarithm of the consumer price index, ${ }^{10}$ excess money eci, $i=1,2,3$, as given by equations ( $2 \mathrm{a}),(2 \mathrm{~b})$ and $(2 \mathrm{c})$, and annual nominal money growth $\Delta_{4} m i$

$$
\Delta_{4} m i_{t}=100\left(m i_{t}-m i_{t-4}\right), \quad i=1,2,3 .
$$

Even before the change in monetary policy in 2000 the SNB was successful in keeping the inflation rate below 2 percent since 1994 . Only due to the dramatic increase in oil prices inflation amounts to about three percent in 2008. There is a clear break in the volatility of the inflation rate in 1994.

10 This transformation is used "because in Switzerland monetary policy decisions are based on percentage changes over the preceding year" (JoRDAN et al., 2001, p. 53). This transformation eliminates also seasonality. 
Figure 3: CUSUM of Squares with 5\% Confidence Bands
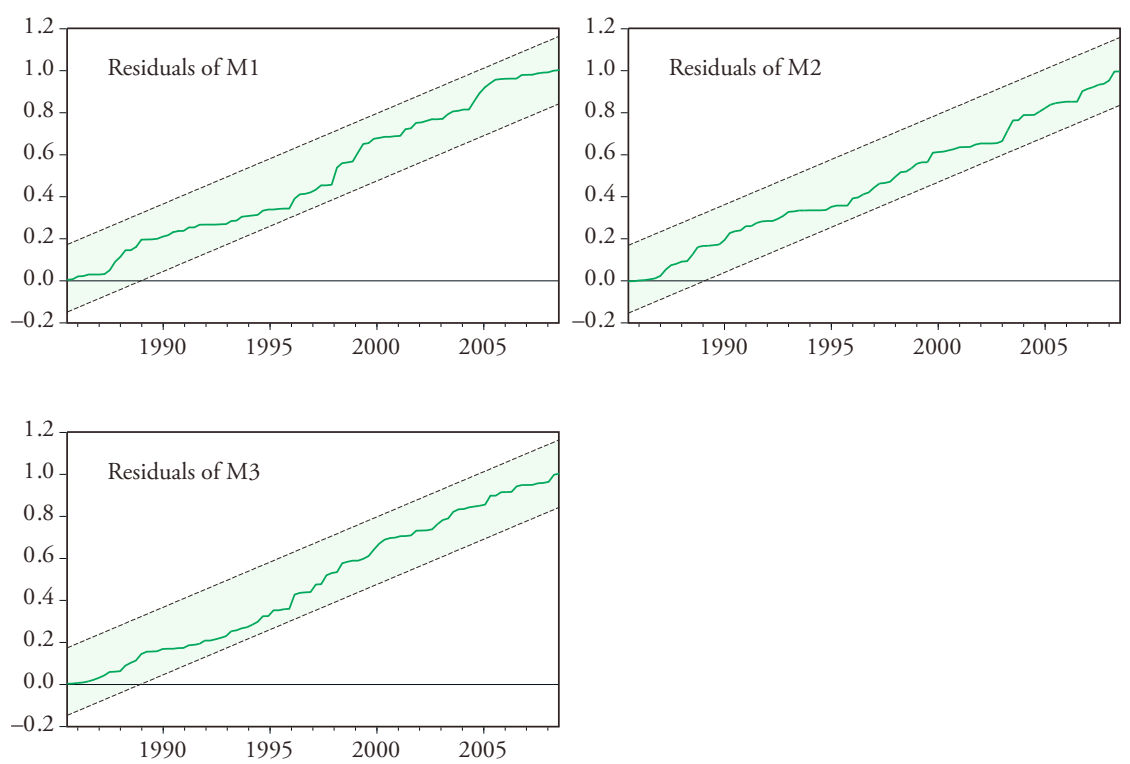

Figure 4a: Recursive Estimates of the Coefficients of the Long-Run Relation for M1
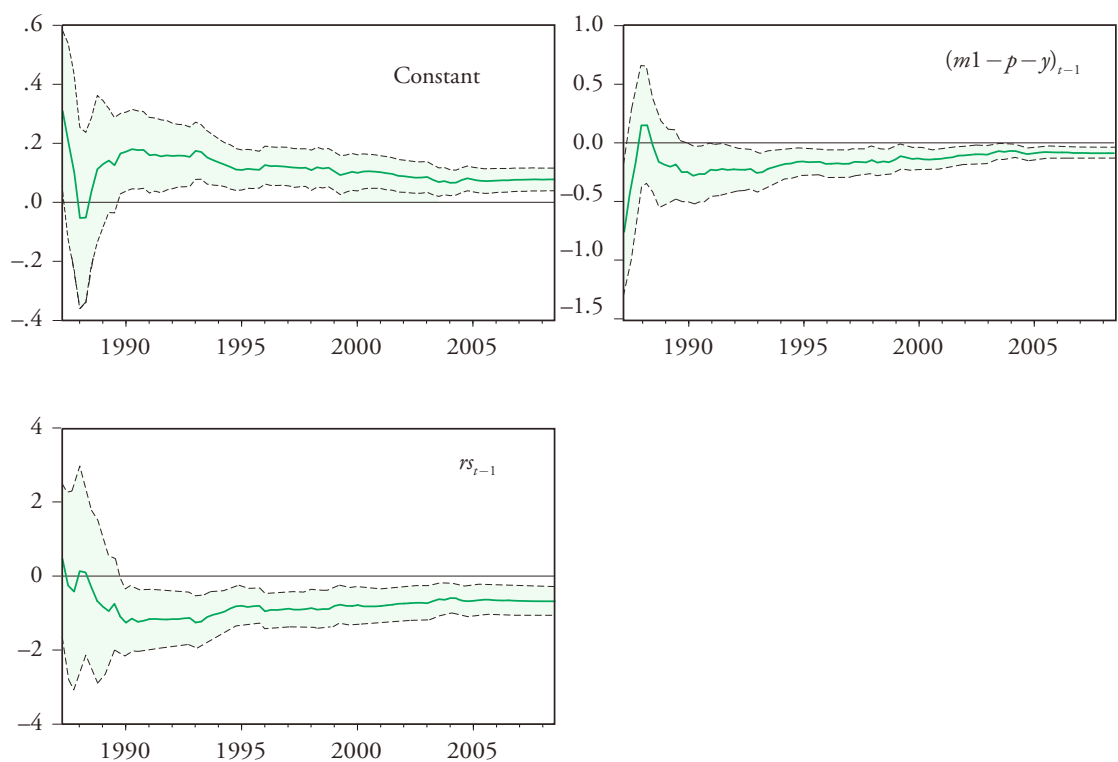
Figure 4b: Recursive Estimates of the Coefficients of the Long-Run Relation for M2
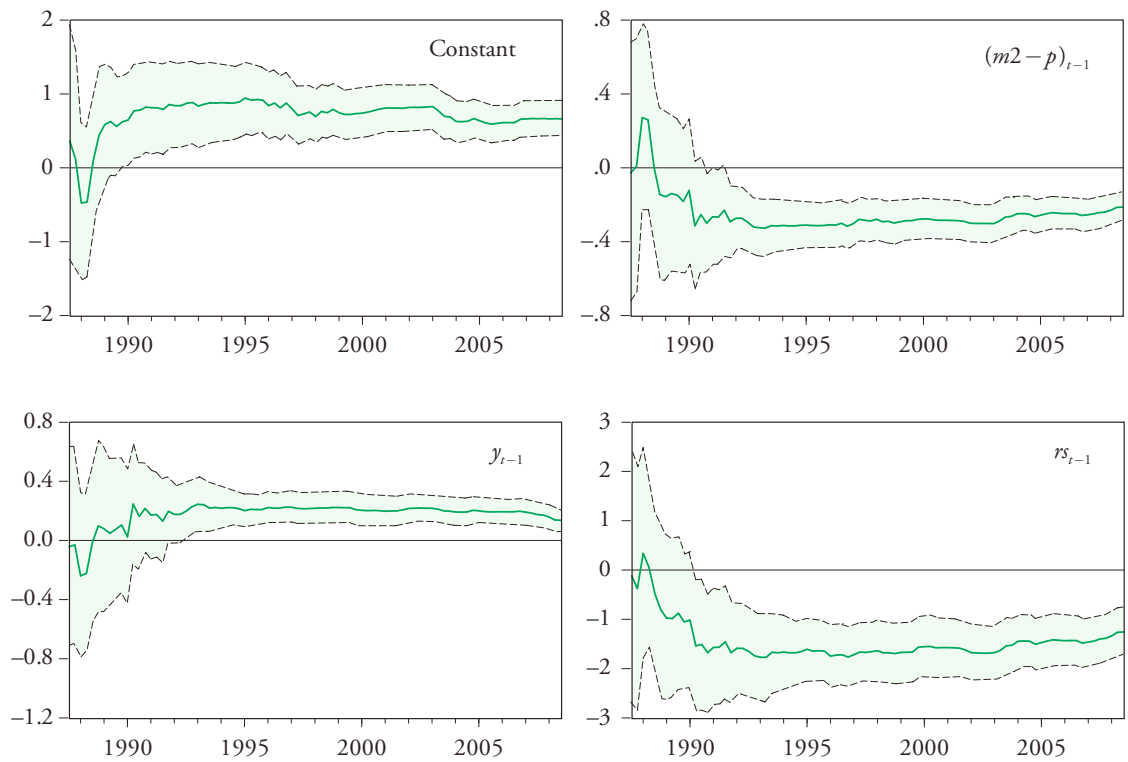

Figure 4c: Recursive Estimates of the Coefficients of the Long-Run Relation for M3
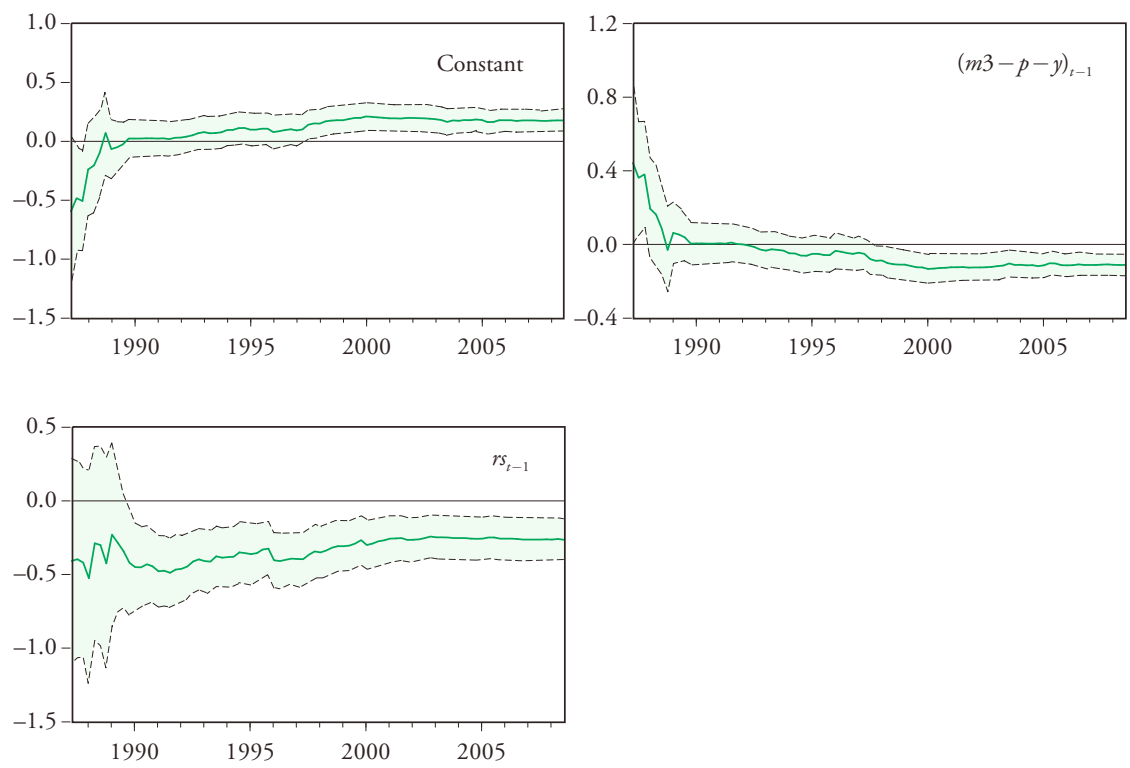
Figure 5a: Consumer Price Inflation and M1 Indicators
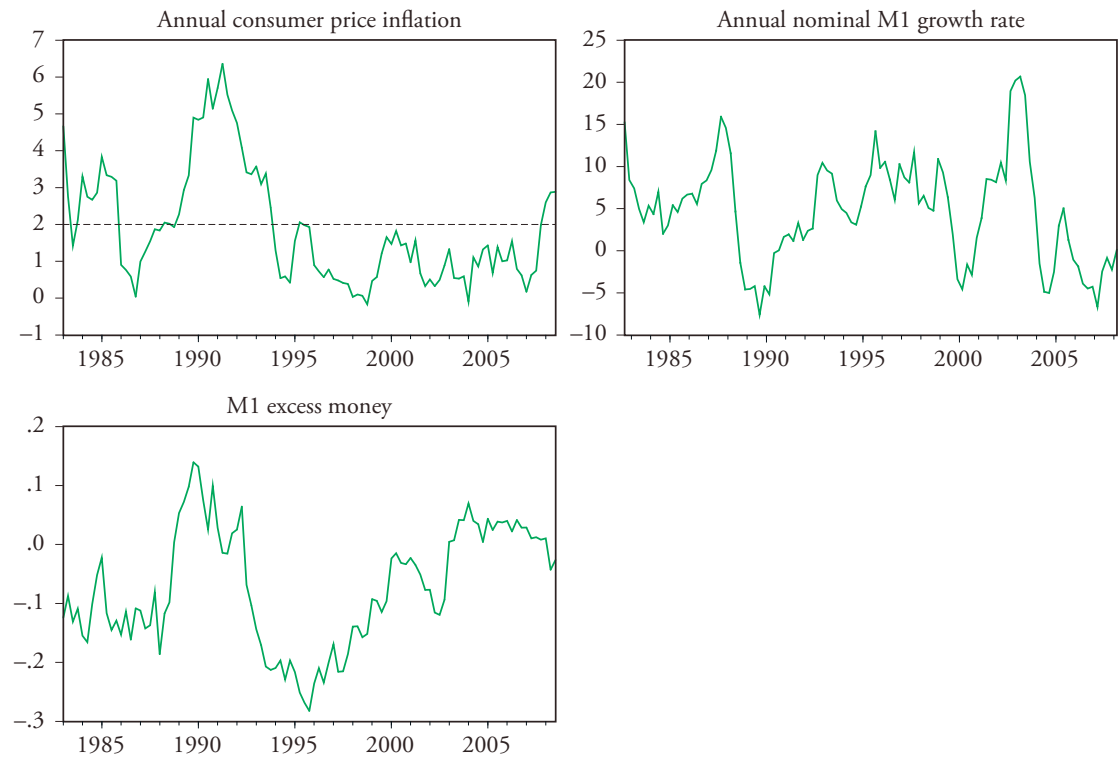

Figure 5b: Consumer Price Inflation and M2 Indicators
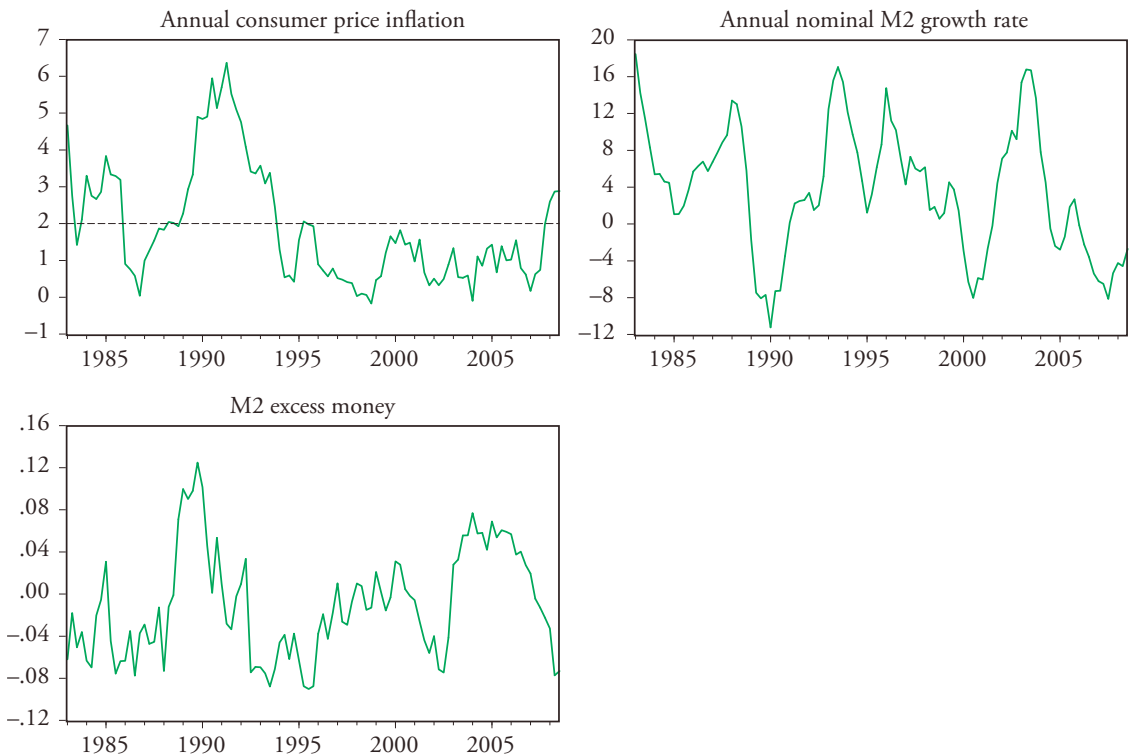
Figure 5c: Consumer Price Inflation and M3 Indicators
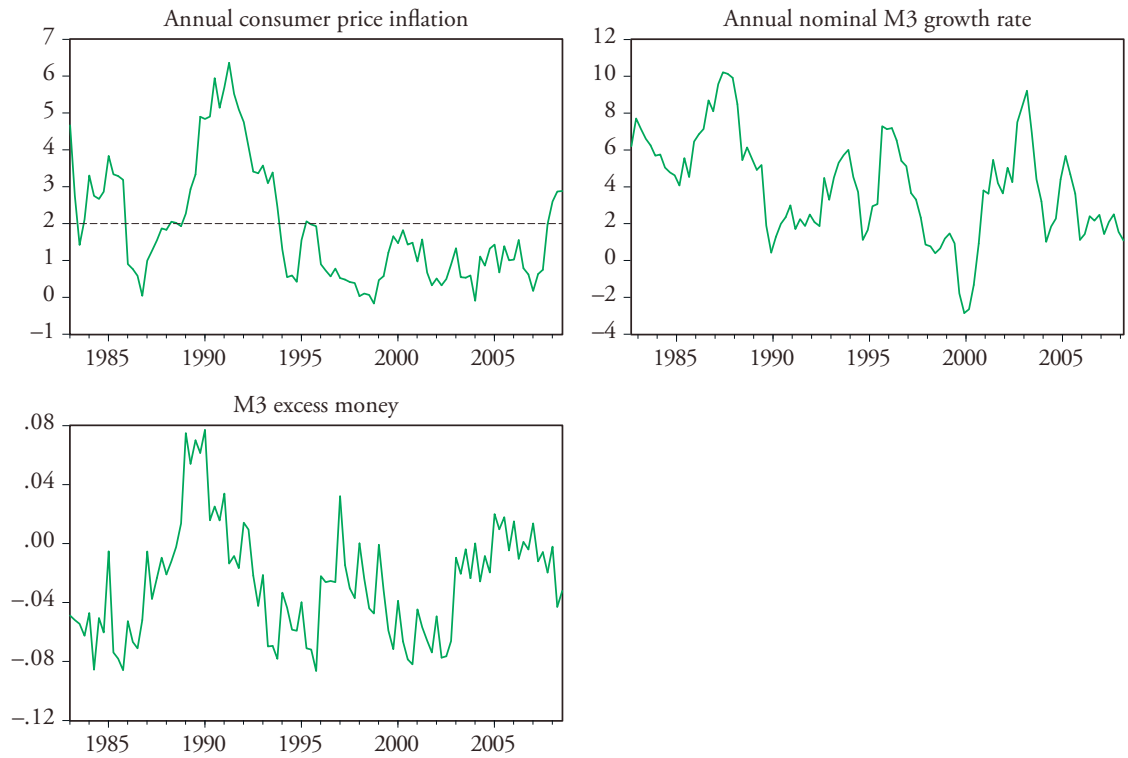

Figure 6 shows cross correlations between inflation and money growth as well as inflation and excess money for all three aggregates. Approximate 95 percent confidence bands are given by -0.2 and +0.2 . It is quite clear that there exist significant positive correlations between lagged excess money and inflation, whereas inflation and lagged money growth are negatively correlated with the exception of M3. For $e c 1$ this correlation is significant for all lags from 1 to 11 with a maximum of about 0.46 at lags 3 to 5 . For $e c 2$ we find significant correlations for the lags from 2 to 12 with a maximum value 0.36 at lags 5 and 6 . Excess money ec 3 is significantly correlated with current inflation at all lags from 1 to 14 with a maximum value of 0.56 at lag 5 . This provides first evidence that excess money of all three aggregates has information content for consumer price inflation.

Pairwise Granger causality tests between monetary indicators and inflation as given in Table 5 confirm the results of the cross correlation analysis. Money growth rates do not significantly influence inflation. The only exception is M3 for the first four lags with a $p$-value of 0.07 . On the other hand, for excess money M1 we can reject the null hypothesis of no Granger causality for lags 4 and 12 at the 10 percent level, but excess money M2 has only a weak influence on inflation 
Figure 6: Cross Correlations 1983(1)-2008(3

Cross correlation between inflation and nominal M1 growth

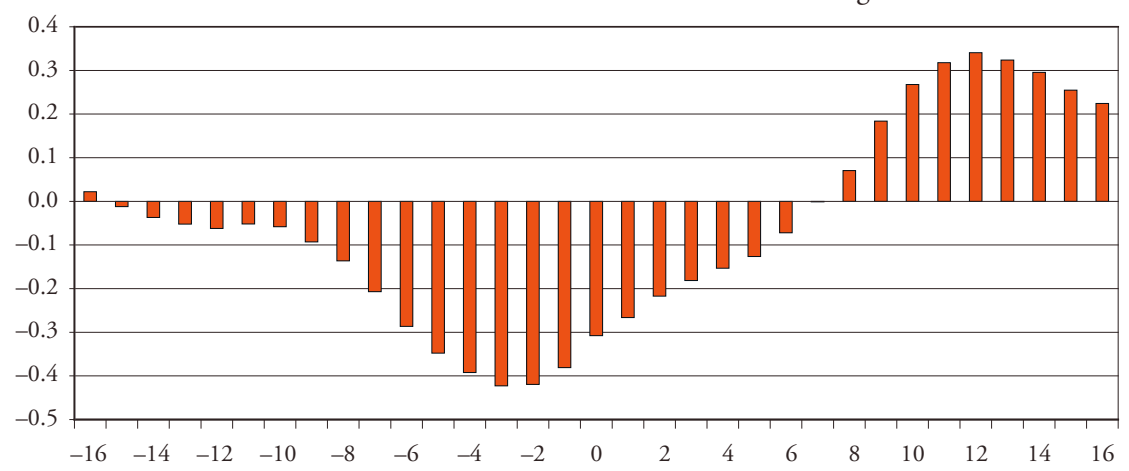

Cross correlation between inflation and nominal M2 growth

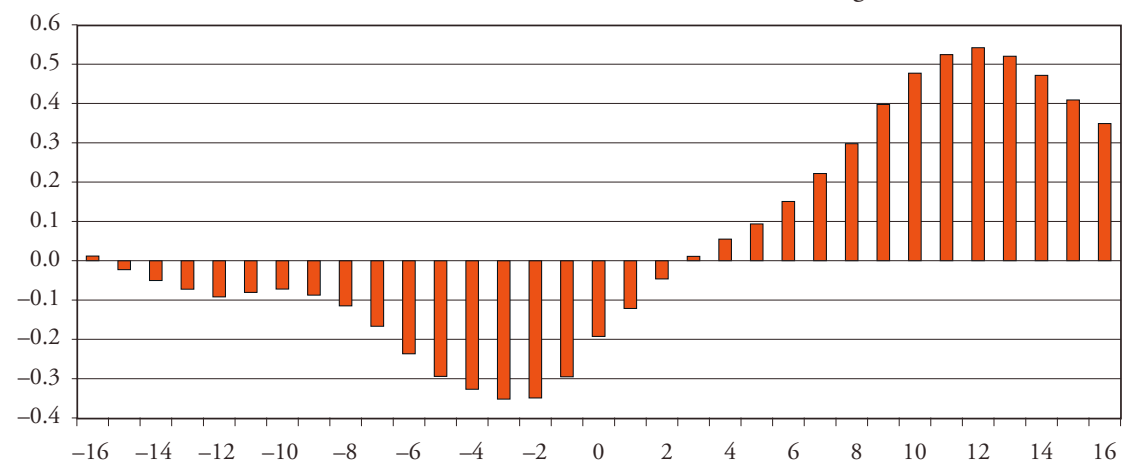

Cross correlation between inflation and nominal M3 growth

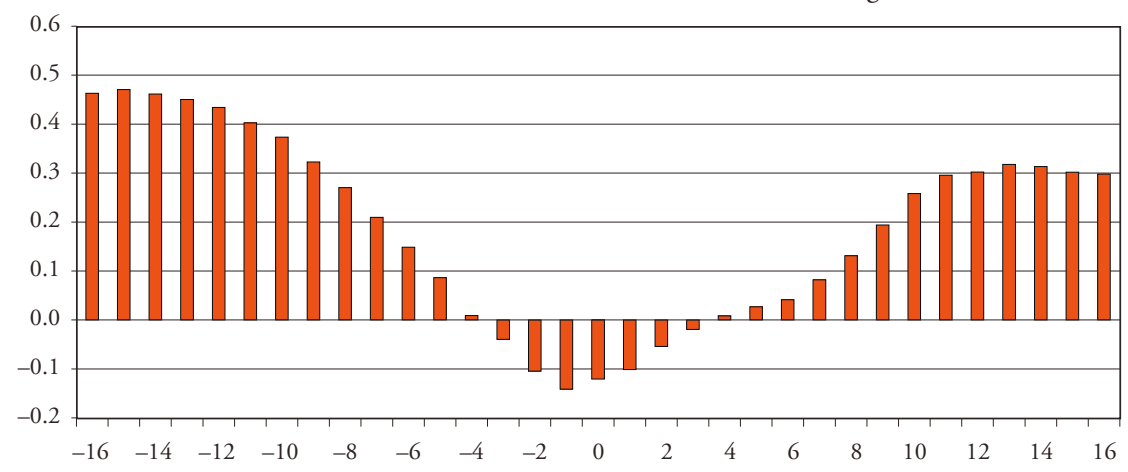


Figure 6 continued

Cross correlation between inflation and M1 excess money

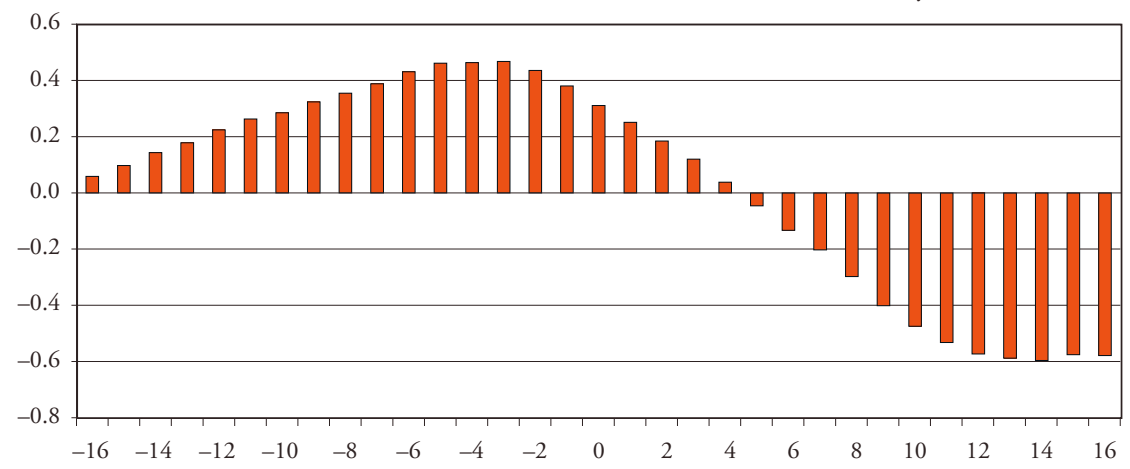

Cross correlation between inflation and M2 excess money

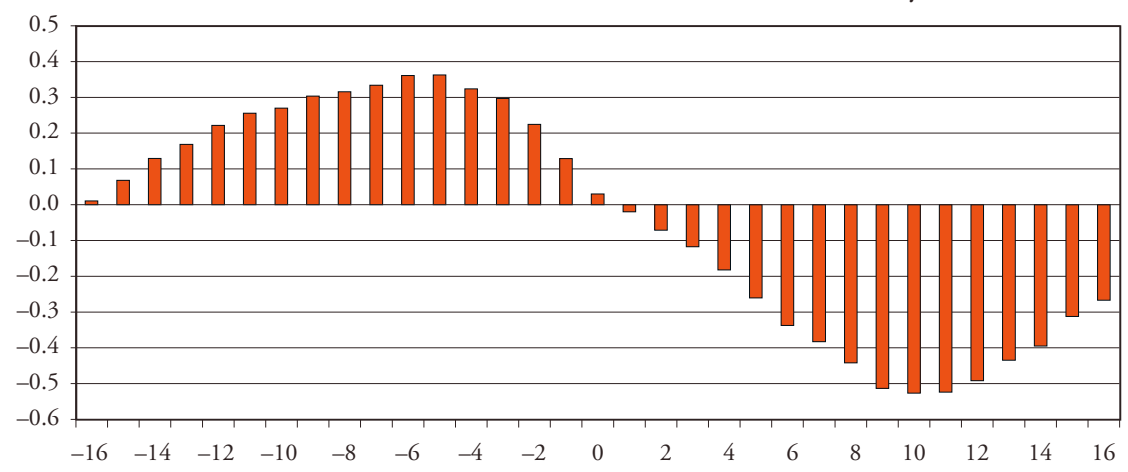

Cross correlation between inflation and M3 excess money

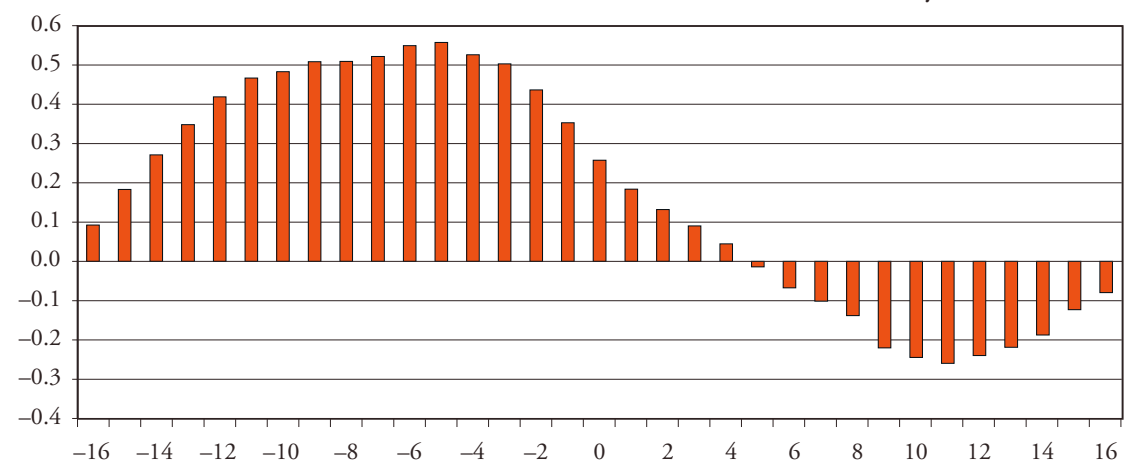


with $p$-values of 0.12 . The strongest influence has excess money M3. Here, the null hypothesis of no Granger causality can be rejected at the 0.04 and 0.03 levels, respectively.

Table 5: Pairwise Granger Causality Tests 1983(1)-2008(3)

\begin{tabular}{lrcc}
\hline & Lags & $\hat{F}$ & p-values \\
\hline$e c 1 \rightarrow \pi$ & 4 & 2.30 & 0.06 \\
& 12 & 1.70 & 0.09 \\
$\Delta_{4} m 1 \rightarrow \pi$ & 4 & 1.43 & 0.23 \\
& 12 & 0.60 & 0.84 \\
$e c 2 \rightarrow \pi$ & 4 & 1.91 & 0.12 \\
& 12 & 1.57 & 0.12 \\
$\Delta_{4} m 2 \rightarrow \pi$ & 4 & 1.82 & 0.13 \\
& 12 & 0.77 & 0.68 \\
$e c 3 \rightarrow \pi$ & 4 & 2.66 & 0.04 \\
& 12 & 2.05 & 0.03 \\
$\Delta_{4} m 3 \rightarrow \pi$ & 4 & 2.28 & 0.07 \\
& 12 & 1.44 & 0.17 \\
\hline
\end{tabular}

\subsection{Forecasting Regressions}

In this section we investigate the information content of all three monetary aggregates for the forecasting horizons of one, two, and three years, which are the most relevant ones for the monetary policy of the SNB. We use the following equation as forecasting model: ${ }^{11}$

$$
\pi_{t+k}=\alpha_{0}+\alpha_{1} \pi_{t}+\alpha_{2} \Delta_{4} m i_{t}+\alpha_{3} e c i_{t}+u_{t}
$$

with $k=4,8,12$ quarters and $i=1,2,3$, respectively. If monetary aggregates have properties of indicator variables we expect significant positive influences of $\Delta_{4} m i$ and/or eci on inflation. To test whether the indicator properties change over time we perform recursive estimates for the period of the new monetary policy framework from 2000 onwards. Equation (3) is estimated for $k=4$ from 1983(1) to 1999(1), then the next estimate runs from 1983(1) to 1999(2), and so on. ${ }^{12} \mathrm{We}$

11 See also Jordan et al. (2001) and Baltensperger et al. (2001). 
simulated the situation that for the predictions only information prior to the forecasting period is available. This means that the error correction terms are each time estimated with data prior to the actual date from which the forecast is made. ${ }^{13}$ Since the error terms in these equations follow moving average processes of order $k-1$ we use the autocorrelation and heteroscedasticity consistent covariance estimator proposed by NEWEY and WeST (1987) to get consistent $t$-values for the regression parameters.

To assess the indicator properties of money growth versus excess money we also estimate equation (3) under the following restrictions:

$$
\begin{aligned}
& \text { R1: } \alpha_{3}=0, \\
& \text { R2: } \alpha_{2}=0,
\end{aligned}
$$

and, as a benchmark,

$$
\text { R0: } \alpha_{2}=\alpha_{3}=0 \text {, }
$$

i.e., we have an $\mathrm{AR}(4)$-process where the coefficients of the first three lags are set to zero. ${ }^{14}$ Under R1 we assess the marginal information content of money growth and under R2 the one of excess money, whereas with equation (3) we evaluate the full information content of M1, M2, and M3, respectively. As a measure for this we use the HanNan-Quinn (HQ) (1979) criterion for the single regressions instead of the adjusted multiple correlation coefficient of the estimated equations. HQ has compared to the $R^{2}$ the advantage that it is a consistent statistic for the goodness of fit of the different regressions. ${ }^{15}$ Having the same dependent variable

12 For $k=8$ the first sample was from 1983(1) to 1998(1), for $k=12$ from 1983(1) to 1997(1). We also performed some preliminary experiments with rolling regressions with 64 observations. The results show no major differences to those of the recursive estimates. Thus, they are not presented here; we concentrated on the recursive models.

13 Because of data revisions, in performing these estimates it would be preferable to use the data actually published at these points of time. Because such revisions are of only minor importance with respect to monetary aggregates and interest rates (as compared, for example, with GDP data), to ease our procedure, for the whole investigation period, we used the data provided by the Swiss National Bank in February 2009.

14 An ADF-test on $\pi$ rejects the unit root hypothesis with a $p$-value of 0.098 .

15 HQ consists of the logarithm of the mean of the squared residuals, which decreases when the number of estimated parameters increases, and of a 'punishment term', which increases when the number of parameters increases. A lower value of the HQ-statistic indicates a better fit of the regression. 
and the same number of observations are preconditions to compare the goodness of fit between M1, M2, and M3 using this measure.

Figures $7 \mathrm{a}$ to $7 \mathrm{c}$ present the recursively estimated HQ-measures for the different versions of equation (3), all the monetary aggregates and the time horizons of one, two, and three years. For M1 (Figure 7a) it is quite clear that the marginal impact of money growth can be neglected. For horizons of two and three years the fits of equation (3) with restriction R1 are even worse than the one of the benchmark model. For all three horizons the HQ-measures of equation (3) are with and without restriction R2 more or less the same. For horizons of two and three years there are no improvements for the years from 2006 to 2008. Thus, for the whole period of the new monetary policy, M1 exhibits only very low indicator properties, which even decrease rapidly after the year 2000. This indicates that M1 might have had reasonable indicator properties under the policy of monetary targeting before 2000 but has lost this property under the new policy regime.

For M2 (Figure 7b) and the one year horizon the different versions of equation (3) show improvements against the benchmark model. For the whole period the HQ-measures of equation (3) without restrictions outperform the other ones. For horizons of two and three years the benchmark model and the model with restriction R1 on the one side and the models with restriction R2 as well as without restrictions on the other side produce nearly the same results. Thus, the improvement stems solely from excess money. Moreover, contrary to our theoretical expectations, the coefficients for $\mathrm{M} 2$ money growth are always negative. Nevertheless, the information content of the M2-measures is permanently higher than the one of the M1-measures, and it improved since 2000.

From Figure 7c it can be derived that for the one year horizon only excess money is able to improve the goodness of fit, whereas for the two other horizons excess money as well as money growth improve the Hannan-Quinn measures, i.e. M3 exhibits from all monetary aggregates the highest information content which is more or less constant over the whole period. Figure 8 presents the recursively estimated coefficients of annual nominal money growth and excess money of equation (3) together with their 95 percent confidence bands for all three horizons. The influence of both variables is very stable over the whole period. Moreover, with the exception of money growth for the one year horizon all coefficients are significantly different from zero and have the expected positive sign.

For central banks indicators of cumulative inflation are important because they deliver information on the potential rise of prices over periods longer than one year. Cumulative or "pipeline" inflation is measured in percent over two and three years as $100 \cdot\left(\Delta_{8} p c_{t+8}\right) / 2$ and $100 \cdot\left(\Delta_{12} p c_{t+12}\right) / 3$. These are the new dependent variables for the different versions of equation (3). Figure 9 presents 
the recursively estimated HQ-measures for assessing the indicator properties of the three monetary aggregates. The results are very similar to the ones given in Figures 7a to 7c for the horizons of two and three years. Again, M3 outperforms M2 and, in particular, M1.

Figure 7a: Recursively estimated Hannan-Quinn measures for M1 with different restrictions of equation (3)
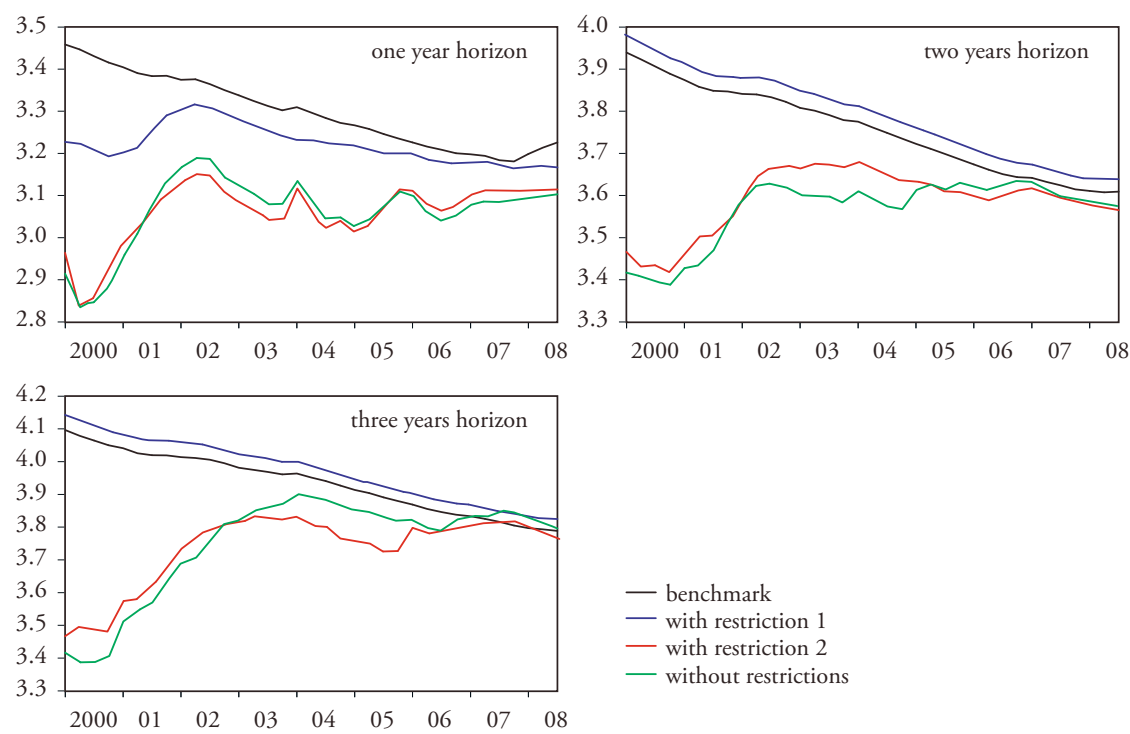

— benchmark

- with restriction 1

with restriction 2

— without restrictions 
Figure 7b: Recursively estimated Hannan-Quinn measures for M2 with different restrictions of equation (3)
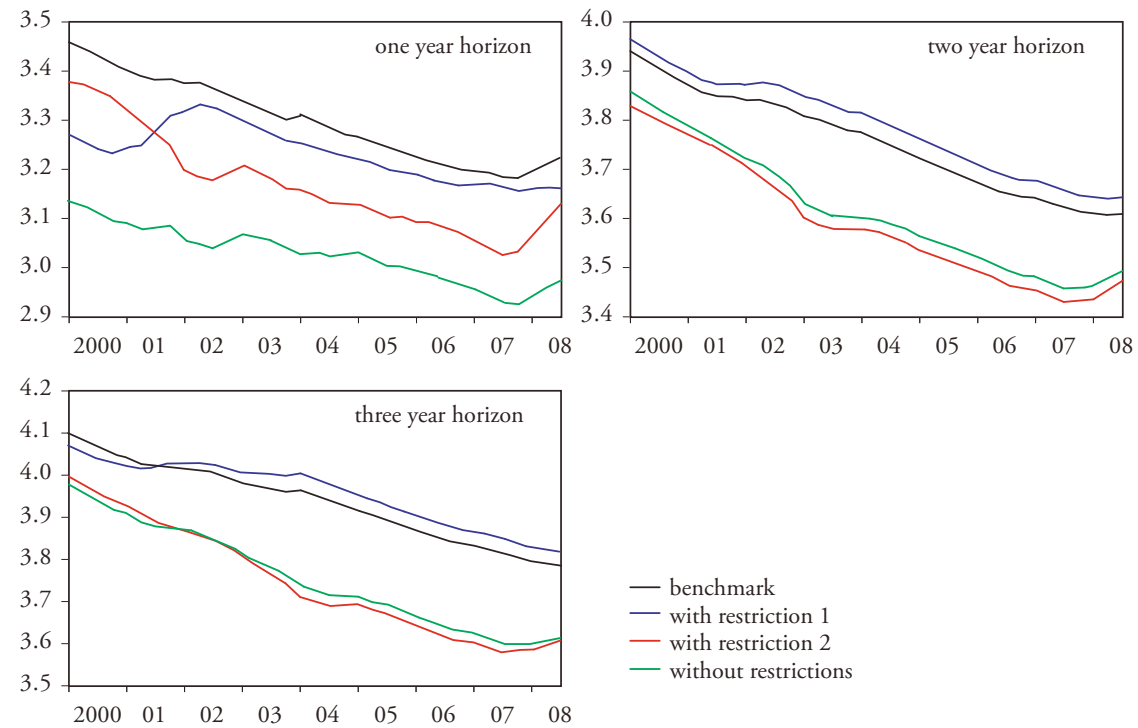

- benchmark

- with restriction 1

- with restriction 2

— without restrictions

Figure 7c: Recursively estimated Hannan-Quinn measures for M3 with different restrictions of equation (3)
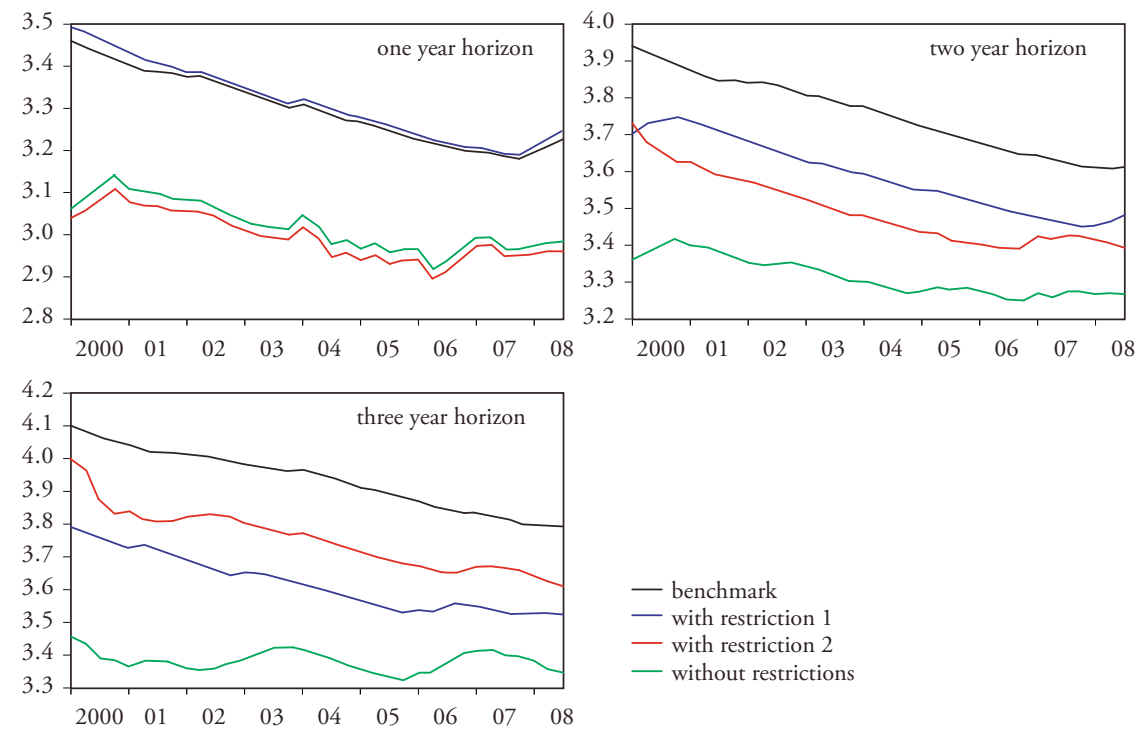

- benchmark

- with restriction 1

- with restriction 2

— without restrictions 
Figure 8: Recursively estimated coefficients of equation (3) for M3 together with their 95 percent confidence bands
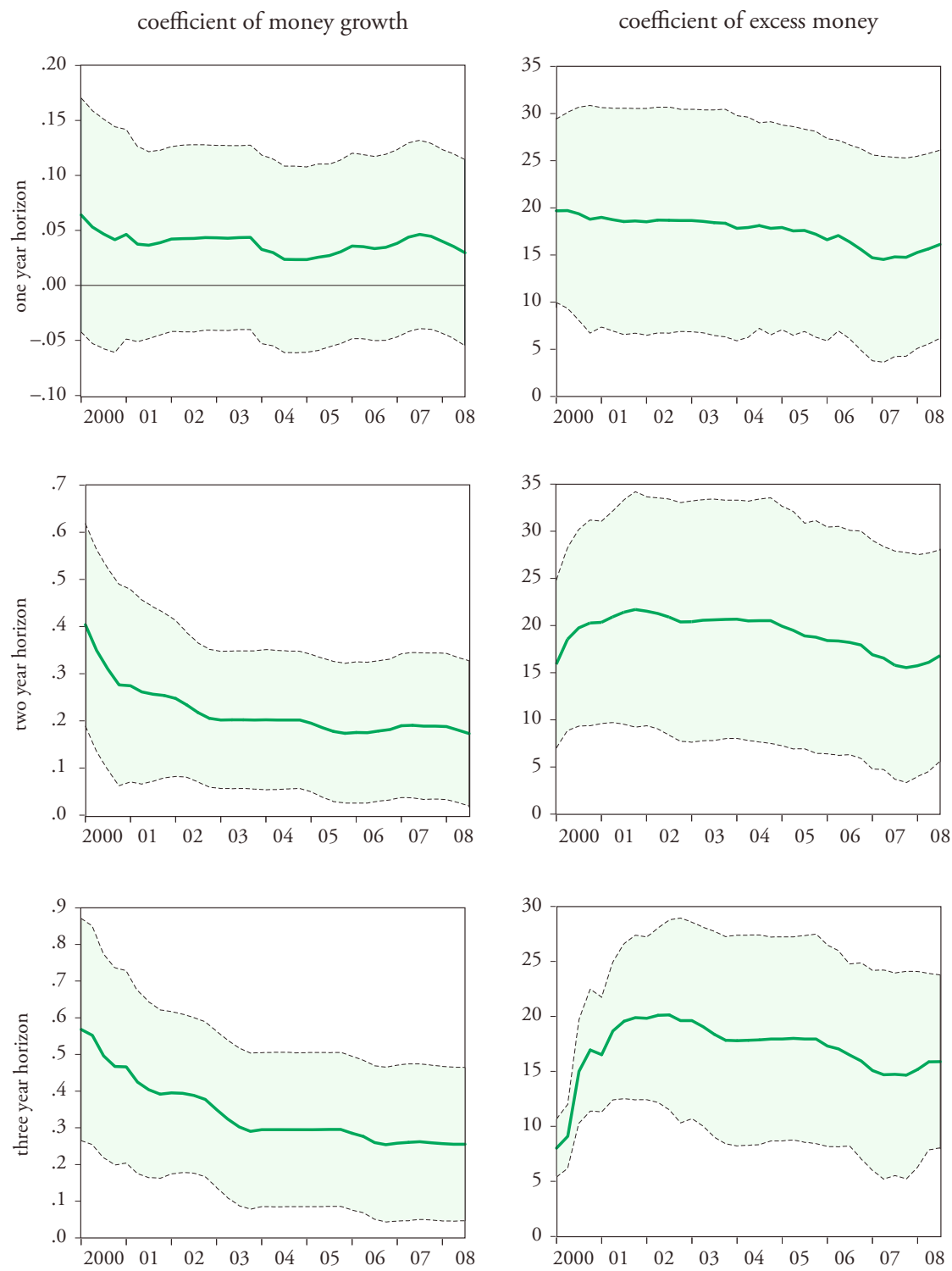
Figure 9: Recursively estimated Hannan-Quinn measures with cumulated inflation as dependent variable
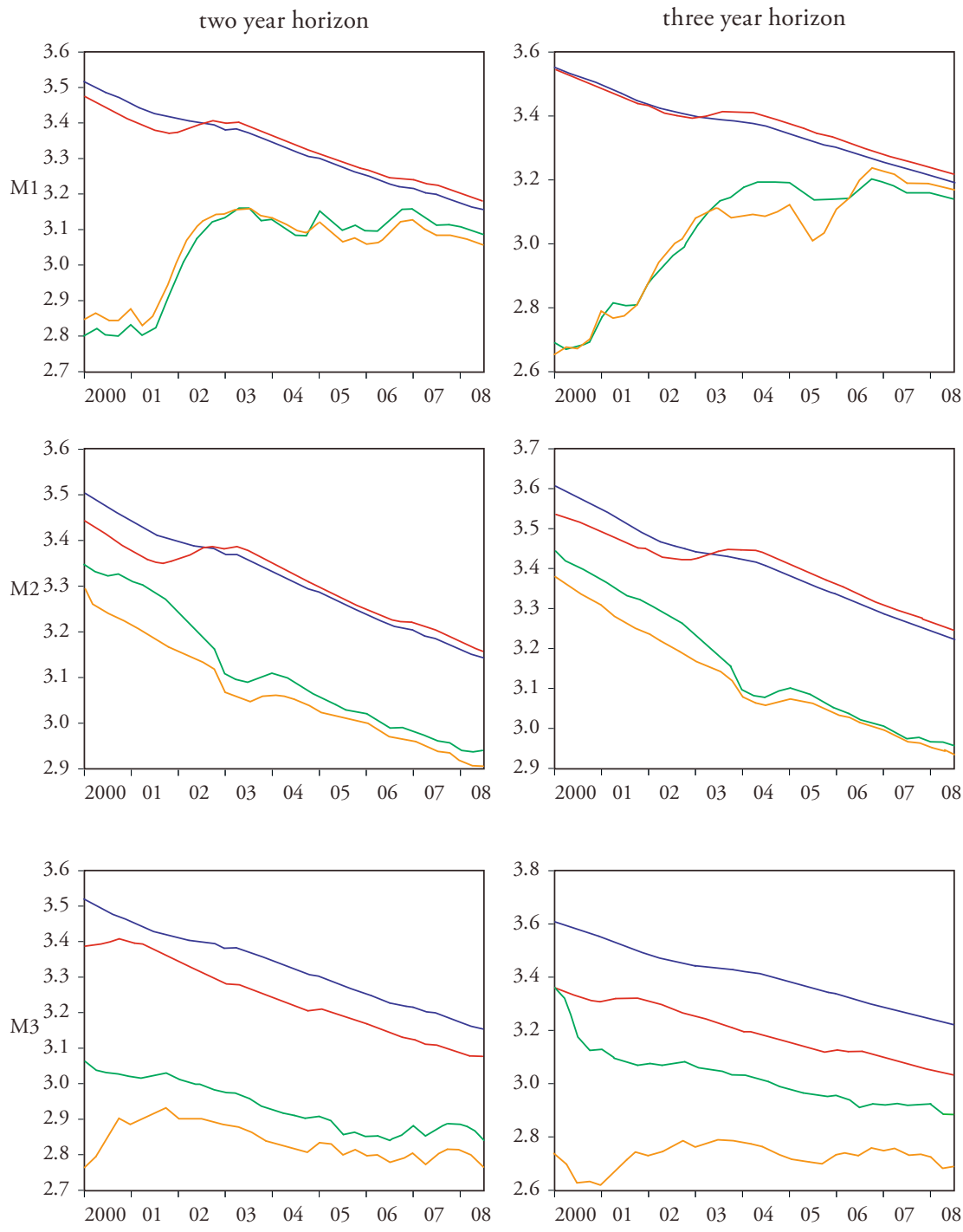

— benchmark

— with restriction 1

— with restriction 2

without restrictions 


\subsection{Out-of-Sample Forecasts}

Given the current situation, one of the major questions is whether the huge expansion of the quantity of money, done by the Swiss National Bank (as well as other central banks) in order to offset the breakdown of the interbank market will create a major inflationary shock. To check this, we can use the forecast equations employed above to perform out-of-sample forecasts for the next years. Given the fact that the measures employing M3 and M2 largely outperformed those with M1 we only use the two former ones for this exercise.

However, as Figure 10 indicates, the actual monetary expansion was smaller than one would expect. First, M3, the measure which, compared to the more narrow measures, proved to have the highest information content for inflation, did not seem to expand very much: While, at the end of the second quarter of 2009, nominal M2 had increased about 31 percent and M1 even about 34 percent compared to the same quarter of 2008, the corresponding increase of M3 was only about 6 percent. Moreover, as Figure 10 shows, M1 as well as M2 decreased since about 2004, and the recent increase more or less offsets this decrease; considering the long-run development the current amounts of both quantities seem to be high but not exceptionally so. Thus, the rather restrictive Swiss monetary policy (with respect to M1 and M2) during recent years allowed the SNB to dramatically increase these two quantities without bringing these clearly above their long-term trends.

Figure 10: Quantity of Money, M1, M2, M3 1983(1)-2009(2)

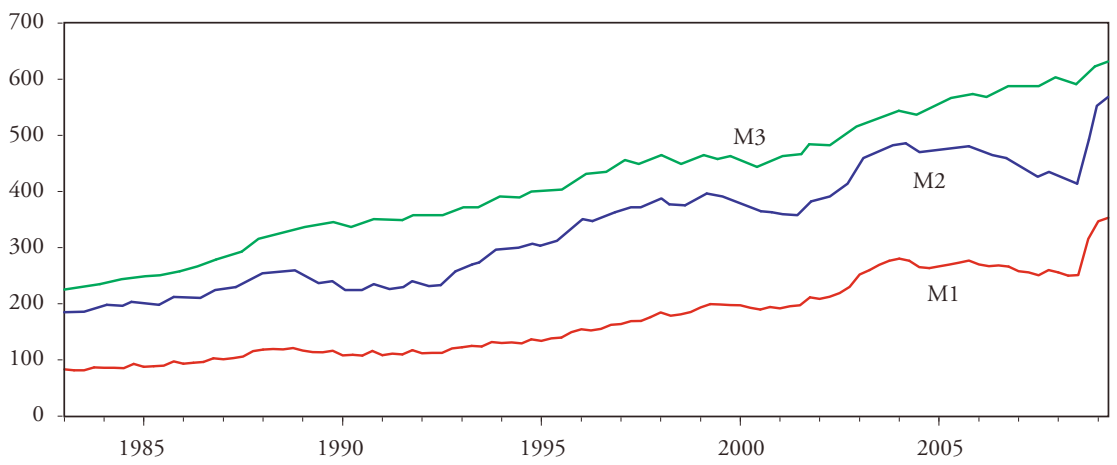


So far, only three quarterly observations for real GDP are available which can be used to reflect the reaction of the Swiss National Bank to the financial crisis. The first question to be asked is whether the money demand equations behind our forecasts remain stable if we include these three observations. The results show a remarkable difference between M2 (as well as M1) and M3. While the estimates for M3 remain very stable and the residuals of the three additional observations are well inside the 95 percent confidence band, the residuals of these three observations are strong outliers in the M2 equation. This is also reflected in the goodness of fit as well as the distribution of the residuals. The adjusted $R^{2}$ measure is only slightly reduced from 0.488 to 0.473 in the enlarged equation for M3, while it is considerably reduced from 0.626 to 0.515 in the M2 equation. The Jarque-Bera statistic does hardly change for M3, with having $p$-values of 0.54 and 0.53 , respectively, while it increases from 2.91 with a $p$-value of 0.23 to 225.96 with a $p$-value below 0.00001 for M2. Moreover, the long-run relation for M2 is strongly influenced by these three additional observations; there are - compared to equation (2b) - considerable changes of the constant term and the income elasticity,

$$
m 2_{t}-p_{t}=\underset{(0.47)}{2.252}+\underset{(0.10)}{0.833} y_{t}-\underset{(0.56)}{5.892} r s_{t}+e c 2^{\prime}{ }_{t},
$$

whereas the long-run relation for M3 - compared to equation (2c) - stays almost the same,

$$
m 3_{t}-p_{t}=\underset{(0.03)}{1.635}+y_{t}-\underset{(0.45)}{2.364 r s_{t}}+e c 3_{t}^{\prime} .
$$

Thus, not only the graphs in Figure 10 show that there is a considerable difference in the behaviour of M2 (as well as M1) and M3.

In the following we tried to investigate the possible implications of changes in the money demand equations as well as the available recent data up to 2009(2) due to the economic crises. We perform inflation forecasts for 2010 and 2011 with three different scenarios:

(i) We used only information available up to 2008(3), i.e. before the outbreak of the economic crises. We estimated the forecast equation (3) for $\pi_{t+8}$ and $\pi_{t+12}$, as well as for the corresponding cumulative inflation over two and three years with data from 1983(1) to 2008(2), applying the equilibrium errors from equations (2b) and (2c), respectively. ${ }^{16}$ We used this equation with the data available up to 2008(2) to generate the two and three years 
ahead forecasts for 2010(2) and 2011(2) presented in rows (1) and (4) of Table 6.

(ii) We employed the same "old" forecast equations but, for performing the same forecasts, we used the newly available data up to 2009(2). The corresponding results are given in rows (2) and (5) of Table 6.

(iii) We re-estimated the forecast equation (3) with the newly available data from 1983(1) to 2009(2) applying the equilibrium errors from equations (2b') and $\left(2 c^{\prime}\right)$ and used these data also to perform the forecasts. The corresponding results are given in rows (3) and (6) of Table 6.

Table 6: Ex Ante Forecasts

\begin{tabular}{|c|c|c|c|c|c|}
\hline \multirow{2}{*}{$\begin{array}{l}\text { Quantity } \\
\text { of Money }\end{array}$} & & \multirow{2}{*}{$\begin{array}{c}\text { End of } \\
\text { estimation period }\end{array}$} & \multirow{2}{*}{$\begin{array}{c}\text { End of } \\
\text { data period }\end{array}$} & \multicolumn{2}{|c|}{ Forecasts for } \\
\hline & & & & $2010(2)$ & 2011(2) \\
\hline \multirow[t]{3}{*}{ M2 } & (1) & $2008(2)$ & $2008(2)$ & $\begin{array}{l}1.11 \\
(1.57)\end{array}$ & $\begin{array}{c}1.27 \\
(1.45)\end{array}$ \\
\hline & (2) & $2008(2)$ & $2009(2)$ & 1.19 & $\begin{array}{c}3.54 \\
(2.08)\end{array}$ \\
\hline & (3) & $2009(2)$ & $2009(2)$ & 0.51 & $\begin{array}{l}2.89 \\
(1.53)\end{array}$ \\
\hline \multirow[t]{3}{*}{ M3 } & (4) & $2008(2)$ & $2008(2)$ & $\begin{array}{c}0.60 \\
(1.48)\end{array}$ & $\begin{array}{c}0.72 \\
(1.21)\end{array}$ \\
\hline & (5) & $2008(2)$ & $2009(2)$ & 0.18 & $\begin{array}{c}0.92 \\
(0.51)\end{array}$ \\
\hline & (6) & $2009(2)$ & $2009(2)$ & 0.23 & $\begin{array}{r}0.84 \\
(0.51)\end{array}$ \\
\hline
\end{tabular}

The numbers in parentheses are the cumulative forecasts over all two or three years, respectively.

The results using M2 as indicator variable are much stronger affected by the recent development due to the economic crises. This holds in particular for the year 2011, while the differences for 2010 are of minor importance. Nevertheless, they are all inside the range between zero and two percent steered by the SNB. For the second quarter of 2010 we get projected inflation rates between 0.5 and 1.6 with M2 and between 0.2 and 1.5 with M3. For the second quarter

16 For performing these forecasts we used the second quarter of 2008 as starting period in order to get comparable one, two and three years ahead forecasts with those ones based on the more recent data because (preliminary) GDP date were only available up to the second quarter of 2009. 
of 2011, however, we now find values ranging from 1.3 to 3.5 with M2 but only from 0.5 to 1.2 with M3. Thus, the M3-results show no evidence that the inflation rate target zone might be violated, while, using the more recent data, the M2-results do strongly indicate that considerable danger exists that the inflation rate will exceed the upper limit of two percent. This discrepancy is, however, not astonishing due to the rather different developments of M2 (as well as M1) and M3 since the third quarter of 2008 as shown in Figure 10. Thus, the year 2011 will provide some evidence whether M2 or M3 is more important for inflation in Switzerland.

\section{Conclusions}

Using quarterly, seasonally unadjusted Swiss data from 1983 to 2008, this paper investigates whether for the different monetary aggregates measures of money growth and or excess money can be used to forecast inflation. After a preliminary data analysis, money demand relations are specified, estimated and tested. For all three aggregates we get very stable relations. Employing error correction models, measures of excess money are derived. Using recursive estimates, indicator properties are assessed for the period of the new monetary policy from 2000 onwards, with time horizons of one, two, and three years. In these calculations, excess money is generally a better predictor than the quantity of money. M2 and M3 clearly outperform M1, while M3 performs somewhat better than M2. Moreover, it is the only aggregate where money growth contributes significantly and with the expected sign in explaining inflation. This confirms the results of Baltensperger et al. (2001) as well as Jordan et al. (2001) which showed the indicator properties of M3 for inflation for the period before 2000, where the SNB performed monetary targeting. Thus, our results justify that the SNB's policy should also rely on (excess money as well as the annual growth rate of) M3 as an indicator variable for inflation today.

Taking into account also the most (available) recent observations that represent the first three quarters of the economic crisis, the money demand function of M3 remains stable while the one for M2 is strongly influenced by these three observations. While in both cases forecasts for 2010 show inflation rates inside the target zone, forecasts based on M2 provide evidence that the upper limit of this zone could be violated in 2011. Forecasts based on M3 do not point in this direction. The reason for this remarkable difference lies in the rather different behaviour of M2 and M3 since the third quarter of 2008; M3 is much less influenced by the additional liquidity provided by the SNB in order to stabilise the money market. 
This result should, however, be interpreted with much care, as it is rather preliminary. Given the fact that just three observations are sufficient to produce major changes in the M2 money demand equation creates some doubts on the stability of the forecast model. To check this, more data are necessary. On the other hand, the fact that there does not seem to be a major impact of the crisis on M3 is at least some evidence in favour of the claim of the SNB that the current crisis and the SNB's policy to fight this crises is not leading to higher inflation in the medium- to long-run. (Also) in this respect, Switzerland might be in a somewhat better position than many other countries.

\section{References}

Assenmacher-Wesche, Katrin (2008), "Modeling Monetary Transmission in Switzerland with a Structural Cointegrated VAR Model", Swiss Journal of Economics and Statistics, 144, pp. 197-246.

Assenmacher, Katrin, and Katarina Juselius (2008), "Modeling Monetary Transmission in Switzerland", mimeo, Swiss National Bank, Zürich 2008.

Baltensperger, Ernst, Thomas J. Jordan and Marcel R. Savioz (2001), "The Demand for M3 and Inflation Forecasts: An Empirical Analysis for Switzerland", Weltwirtschaftliches Archiv, 137, pp. 244-272.

Banerjee, Anindya, Juan J. Dolado and Ricardo Mestre (1998), "ErrorCorrection Mechanism Tests for Cointegration in a Single-Equation Framework", Journal of Time Series Analysis, 19, pp. 267-284.

Baumol, William J. (1952), "The Transaction Demand for Cash: An Inventory Theoretic Approach”, Quarterly Journal of Economics, 66, pp. 545-556.

Brüggemann, Ralf, and Helmut Lütkepohl (2005), "Practical Problems with Reduced Rank ML Estimators for Cointegration Parameters and a Simple Alternative", Oxford Bulletin of Economics and Statistics, 67, pp. 673-690.

Carstensen, Kai, Jan Hagen, Oliver Hossfeld and Abelardo S. Neaves (2009), "Money Demand Stability and Inflation Prediction in the Four Largest EMU Countries", Scottish Journal of Political Economy, 56, pp.73-93.

Ericsson, Neil R. (1998), "Empirical Modeling of Money Demand”, Empirical Economics, 23, pp. 295-315, reprinted in: H. Lütkepohl and J. Wolters (eds), Money Demand in Europe, Heidelberg 1999, pp. 29-49.

Estrella, Arturo, and Frederic S. Mishrin (1997), "Is There a Role for Monetary Aggregates in the Conduct of Monetary Policy?", Journal of Monetary Economics, 40, pp. 279-304, reprinted in: F.S. Mishkin (ed.), Monetary Policy Strategy, Cambridge (Mass.) 2007, pp. 109-132. 
Friedman, Milton (1963), Inflation: Causes and Consequences, New York.

Gerlach, Stefan and Lars E.O. Svensson (2003), "Money and Inflation in the Euro Area: A Case for Monetary Indicators?", Journal of Monetary Economics, 50, pp. 1649-1672.

Gerlach-Kristen, Petra (2001), “The Demand for Money in Switzerland”, Swiss Journal of Economics and Statistics, 137, pp. 535-554.

Hannan, Edward J., and Barry G. Quinn (1979), "The Determination of the Order of an Autoregression", Journal of the Royal Statistical Society B, 41, pp. 190-195.

Hofmann, Boris (2006), "Do Monetary Indicators (Still) Predict Euro Area Inflation”, Deutsche Bundesbank, Discussion Paper, Series 1, No 18.

Hylleberg, Svend, Robert Engel, Clive W.J. Granger and Byung S. Yoo (1990), "Seasonal Integration and Cointegration", Journal of Econometrics, 44, pp. 215-238.

Johansen, Søren (1995), Likelihood-Based Inference in Cointegrated Vector Autoregressive Models, Oxford.

Jordan, Thomas J., Michel Peytrignet and Georg Rich (2001), "The Role of M3 in the Policy Analysis of the Swiss National Bank", in: H.J. Klöckers and C. Willeke (eds), Monetary Analysis: Tools and Applications, Frankfurt, pp. 47-62.

Jordan, Thomas J., Michel Peytrignet and Enzo Rossi (2010), “Ten Years' Experience with the Swiss National Bank's Monetary Policy Strategy", Swiss Journal of Economics and Statistics, 146, 1, pp.9-90.

Juselius, Katarina (1999), "Models and Relations in Economics and Econometrics", Journal of Economic Methodology, 6, pp. 259-290.

Kaufmann, Sylvia and Peter Kugler (2008), "Does Money Matter for Inflation in the Euro-Area?", Contemporary Economic Policy, 26, pp. 590-606.

Kirchgässner, Gebhard, and Jürgen Wolters (1992), "Implications of Temporal Aggregation on the Relation Between Two Time Series", Statistische Hefte/Statistical Papers, 33, pp. 1-19.

Kirchgässner, Gebhard, and Jürgen Wolters (2007), Introduction to Modern Time Series Analysis, Berlin/Heidelberg/New York 2007.

MacKinnon, James G. (1996), "Numerical Distribution Functions for Unit Root and Cointegration Tests", Journal of Applied Econometrics, 11, pp. 601-618.

Nelson, Edward (2003), "The Future of Monetary Aggregates in Monetary Policy Analysis", Journal of Monetary Economics, 50, pp. 1029-1059.

Newey, Whitney K., and Kenneth D. West (1987), "A Simple Positive Definite Heteroscedasticity and Autocorrelation Consistent Covariance Matrix", Econometrica, 55, pp.703-708. 
Peytrignet, Michel and Christof Stahel (1998), "Stability of Money Demand in Switzerland: A Comparison of the M2 and M3 Cases", Empirical Economics, 23, pp. 437-454, reprinted in: H. Lütkepohl and J. Wolters (eds), Money Demand in Europe, Heidelberg 1999, pp. 171-188.

Rajaguru, Gulasekaran, and Tilak Abeysinghe (2008), "Temporal Aggregation, Cointegration and Causality Inference", Economics Letters, 101, pp. 223-226.

Reynard, Samuel (2007), "Maintaining Low Inflation: Money, Interest Rates, and Policy Stance", Journal of Monetary Economics, 54, pp. 1441-1471.

Schwarz, Gideon (1978), "Estimating the Dimension of a Model", Annals of Statistics, 6 (1978), pp. 461-464.

Stock, James H. (1987), "Asymptotic Properties of Least-Squares Estimators of Cointegrating Vectors", Econometrica, 55, pp. 1035-1056.

Tobin, James (1956), “The Interest Elasticity of Transactions Demand for Cash”, Review of Economics and Statistics, 38, pp. 241-247.

Trecroci, Carmine, and Juan L. Vega (2002), “The Information Content of M3 for Future Inflation in the Euro Area”, Weltwirtschaftliches Archiv, 138, pp. $22-53$.

\section{SUMMARY}

Using Swiss data from 1983 to 2008, this paper investigates whether growth rates of the different measures of the quantity of money and or excess money can be used to forecast inflation. After a preliminary data analysis, money demand relations are specified, estimated and tested. Then, employing error correction models, measures of excess money are derived. Using recursive estimates, indicator properties of monetary aggregates for inflation are assessed for the period from 2000 onwards, with time horizons of one, two, and three years. In these calculations, M2 and M3 clearly outperform M1, and excess money is generally a better predictor than the quantity of money. Taking into account also the most (available) recent observations that represent the first three quarters of the economic crisis, the money demand function of M3 remains stable while the one for M2 is strongly influenced by these three observations. While in both cases forecasts for 2010 show inflation rates inside the target zone between zero and two percent, and the same holds for forecasts based on M3 for 2011, forecasts based on M2 provide evidence that the upper limit of this zone might be violated in 2011. 